\title{
Article \\ Follicular Helper T Cells Remodel the Immune Microenvironment of Pancreatic Cancer via Secreting CXCL13 and IL-21
}

\author{
Xuan Lin $1,2,3,4,+$, Longyun Ye ${ }^{1,2,3,4,+}$, Xu Wang ${ }^{1,2,3,4,+} \mathbb{D}$, Zhenyu Liao ${ }^{1,2,3,4}$, Jia Dong ${ }^{1,2,3,4}$, Ying Yang ${ }^{1,2,3,4}$, \\ Rulin Zhang ${ }^{5}$, Hao Li 1,2,3,4, Pengcheng Li 1,2,3,4, Lei Ding 1,2,3,4, Tianjiao Li 1,2,3,4, Wuhu Zhang 1,2,3,4, \\ Shuaishuai Xu 1,2,3,4, Xuan Han 1,2,3,4, Huaxiang Xu 1,2,3,4, Wenquan Wang 1,2,3,4, Heli Gao 1,2,3,4, \\ Xianjun Yu ${ }^{1,2,3,4, *}$ and Liang Liu $1,2,3,4, *$
}

check for

updates

Citation: Lin, X.; Ye, L.; Wang, X.; Liao, Z.; Dong, J.; Yang, Y.; Zhang, R.; Li, H.; Li, P.; Ding, L.; et al. Follicular Helper T Cells Remodel the Immune Microenvironment of Pancreatic Cancer via Secreting CXCL13 and IL-21. Cancers 2021, 13, 3678. https:/ / doi.org/10.3390/cancers13153678

Academic Editor: David Wong

Received: 3 June 2021

Accepted: 14 July 2021

Published: 22 July 2021

Publisher's Note: MDPI stays neutral with regard to jurisdictional claims in published maps and institutional affiliations.

Copyright: (c) 2021 by the authors. Licensee MDPI, Basel, Switzerland. This article is an open access article distributed under the terms and conditions of the Creative Commons Attribution (CC BY) license (https:// creativecommons.org/licenses/by/ $4.0 /)$.
1 Department of Pancreatic Surgery, Shanghai Cancer Center, Fudan University, Shanghai 200032, China; linxuan@fudanpci.org (X.L.); yelongyun@fudanpci.org (L.Y.); wangxu2013@fudan.edu.cn (X.W.); liaozhenyu@fudanpci.org (Z.L.); dongjia@fudanpci.org (J.D.); yangying@fudanpci.org (Y.Y.); lihao@fudanpci.org (H.L.); lipengcheng@fudanpci.org (P.L.); dinglei@fudanpci.org (L.D.); litianjiao@fudanpci.org (T.L.); zhangwuhu@fudanpci.org (W.Z.); xushuaishuai@fudanpci.org (S.X.); hanxuan@fudanpci.org (X.H.); xuhuaxiang@fudanpci.org (H.X.); wangwenquan@fudanpci.org (W.W.); gaoheli@fudanpci.org (H.G.)

2 Department of Oncology, Shanghai Medical College, Fudan University, Shanghai 200032, China

3 Shanghai Pancreatic Cancer Institute, Shanghai 200032, China

4 Pancreatic Cancer Institute, Fudan University, Shanghai 200032, China

5 Department of Laboratory Medicine, Shanghai General Hospital, Shanghai 200080, China; rulin_zhang@163.com

* Correspondence: yuxianjun@fudanpci.org (X.Y.); liuliang@fudanpci.org (L.L.); Tel./Fax: +86-21-6403-1446 (X.Y.); +86-21-6403-1446 (L.L.)

+ All of the authors contributed equally to this work.

Simple Summary: The immunosuppressive microenvironment is closely related to the poor prognosis of patients with PDAC. Tfh cells play an anti-tumor function in various malignant solid tumors; however, the role of Tfh cells in PDAC has not been determined. In this study, we aimed to explore the function of Tfh cells in PDAC, and revealed a novel immunosuppressive mechanism mediated by Tfh cells. Tfh cells promoted the formation of an immunoactive tumor microenvironment by secreting CXCL13 and IL-21, and the high infiltration of Tfh cells correlated with better patient prognosis. However, the anti-tumor function of Tfh cells was inhibited by the PD-L1/PD-1 signaling pathway. Neoadjuvant chemotherapy could further reverse the function of Tfh cells. Our results provided new strategies to remodel the immunoactive tumor microenvironment of PDAC.

Abstract: Immunosuppression is an important factor for the poor prognosis of pancreatic ductal adenocarcinoma (PDAC). Follicular helper T cells (Tfh cells) play an anti-tumor role in various malignant solid tumors and predict better patient prognosis. In the present study, we aimed to determine the immunosuppressive mechanism associated with Tfh cells and explore a new strategy to improve the tumor microenvironment of PDAC. Flow cytometry was used to detect the infiltration and proportion of Tfh cells in tumor tissues and peripheral blood from patients with PDAC. The spatial correlations of Tfh cells with related immune cells were evaluated using immunofluorescence. The function of Tfh cells was examined using in vitro and in vivo model systems. The high infiltration of Tfh cells predicted better prognosis in patients with PDAC. Tfh cells recruited CD8 ${ }^{+} \mathrm{T}$ cells and B cells by secreting C-X-C motif chemokine ligand 13 (CXCL13), and promoted the maturation of B cells into antibody-producing plasma cells by secreting interleukin 21 (IL-21), thereby promoting the formation of an immunoactive tumor microenvironment. The function of Tfh cells was inhibited by the programmed cell death 1 ligand 1 (PD-L1)/programmed cell death 1 (PD-1) signaling pathway in PDAC, which could be reversed using neoadjuvant chemotherapy. Treatment with recombinant CXCL13, IL-21 and Tfh cells alleviated tumor growth and enhanced the infiltration of CD8 ${ }^{+} \mathrm{T}$ cells and B cells, as well as B cell maturation in a PDAC mouse model. Our results revealed the important role of Tfh cells in mediating anti-tumor cellular immunity and humoral immunity in PDAC via secreting CXCL13 and IL-21 and determined a novel mechanism of immunosuppression in PDAC. 
Keywords: follicular helper T cells; immune microenvironment; immunosuppression; neoadjuvant chemotherapy; pancreatic ductal adenocarcinoma

\section{Introduction}

Pancreatic ductal adenocarcinoma (PDAC) is a threat to human life, being a highly invasive and metastatic malignancy [1]. PDAC is generally resistant to chemotherapy and immunotherapy, with a five-year overall survival rate of less than $10 \%[1,2]$. PDAC is a typical "cold" tumor, characterized by an immunosuppressive microenvironment $[2,3]$. Previous studies have revealed that the absence and low activation of $\mathrm{CD} 8^{+} \mathrm{T}$ cells induced by the matrix composition, especially myeloid cell infiltration, contribute to the immunosuppressive microenvironment [4-7], indicating the significant roles of $\mathrm{T}$ cells in the PDAC immune microenvironment. However, the other cellular components in the microenvironment have barely been investigated. In particular, the anti-tumor role of $B$ cells in establishing the immune response in PDAC has come to light recent years [8-11]; however, the precise regulatory mechanisms remain unexplored. In the present study, we aimed to investigate a novel follicular helper T cells (Tfh cells)-mediated mechanism of immunosuppression in PDAC.

Tfh cells are a subgroup of $\mathrm{CD} 4^{+} \mathrm{T}$ cells discovered in 2000, which are required helpers of $\mathrm{B}$ cell maturation and antibody production, playing a protective or pathogenic role in anti-infective immune responses or autoimmune diseases [12]. In addition, Tfh cells are a component of tumor-associated tertiary lymphoid structures (TLSs) [13] in the tumor microenvironment. In recent years, the infiltration of Tfh cells was discovered to correlate positively with better prognosis in patients with malignant tumors, which mainly depended on the recruitment of C-X-C motif chemokine ligand 13 (CXCL13) to CD8 ${ }^{+} \mathrm{T}$ cells and B cells [14-18]. In parallel, Tfh cells secrete the cytokine interleukin 21 (IL-21), which promotes the differentiation and maturation of $B$ cells into plasma cells that produce tumor antigen-specific antibodies and thus, enhance the long-term anti-tumor immune response $[15,19,20]$. Therefore, we hypothesized that $\mathrm{Tfh}$ cells directly regulate $\mathrm{CD} 8^{+} \mathrm{T}$ cells and B cells to remodel the immune microenvironment in PDAC.

In the present study, we investigated the infiltration of Tfh cells in PDAC and uncovered their anti-tumor role using in vitro and in vivo model systems. The high infiltration of Tfh cells correlated positively with better prognosis in patients with PDAC. Tfh cells increased the infiltration of CD8 ${ }^{+} \mathrm{T}$ cells and $\mathrm{B}$ cells by secreting CXCL13, and promoted the maturation of $\mathrm{B}$ cells into plasma cells that produced tumor antigen-specific antibodies by secreting IL-21, thereby enhancing anti-tumor cellular immunity and the long-term humoral immunity response. Notably, the anti-tumor effect of Th cells was impaired by programmed cell death 1 ligand 1 (PD-L1)/programmed cell death 1 (PD-1) signaling, which could be reversed using neoadjuvant chemotherapy. Lastly, ectopic Tfh cells induced an immunoactive microstructure in mouse models of PDAC. Taken together, our results revealed an important role of Th cells in anti-tumor immunity and a novel Tfh-mediated mechanism of immunosuppression, providing a new strategy to transform PDAC from an immunosuppressive "cold" tumor to an immunologically active "hot" tumor.

\section{Materials and Methods}

\subsection{Human Specimens}

Tumor tissue specimens, peripheral blood samples, and spleens were acquired from Fudan University Shanghai Cancer Center. Intra-tumor tissues and peripheral blood samples were obtained from patients with PDAC during curative intent surgery. Spleens were acquired from patients with pancreatic tail cancer during surgery. All specimens were confirmed by postoperative pathology. The disease stage was defined according to the 8th edition American Joint Committee on Cancer (AJCC) stage system, and the multiple 
samples of different tumor stages used in the study were acquired from different patients. Detailed clinical data on the patient cohort are shown in Table S1.

Fragments $\left(1-2 \mathrm{~mm}^{3}\right)$ of fresh tumor tissue specimens were digested in Roswell Park Memorial Institute (RPMI) 1640 medium with Liberase TL $(0.1 \mathrm{mg} / \mathrm{mL}$, Roche Diagnostics, Indianapolis, IN, USA) and DNase I (10 U/mL, Roche Diagnostics) for $30 \mathrm{~min}$. Single cells were filtered through $70 \mu \mathrm{m}$ cell strainers (BD Biosciences, San Jose, CA, USA) and re-suspended in Percoll (40\%, GE Healthcare, Chicago, IL, USA) for gradient centrifugation. Peripheral blood samples were diluted in phosphate-buffered saline (PBS) and added to Ficoll (GE Healthcare) for gradient centrifugation to obtain peripheral blood mononuclear cells (PBMCs). Spleens were ground on a $70 \mu \mathrm{m}$ cell strainer, filtered, and re-suspended in red blood cell lysate (BD Biosciences) to remove red blood cells.

\subsection{Mice}

Male C57BL/ 6 mice (5 weeks old) purchased from Shanghai Jihui Co. (Shanghai, China) were bred under the specific pathogen-free (SPF) conditions. The armpit of each mouse was injected subcutaneously with $1 \times 10^{7}$ PANC-2 cells in $200 \mu \mathrm{L}$ of PBS (pH 7.4). Three days later, the mice in the control group were injected with PBS, and the mice in the three experimental groups were injected with recombinant mouse (rm) CXCL13 (5 $\mu \mathrm{g}$, Peprotech, Rocky Hill, NJ, USA), rmIL-21 (5 $\mu$ g, Peprotech) and $1 \times 10^{5}$ Tfh cells, separately, via the tail vein every 3 days and euthanized 2 weeks later. The mice weight and tumor measurements were conducted every two days and the tumor volume $\left(\mathrm{mm}^{3}\right)$ was estimated as (length $\times$ width $\left.^{2}\right) / 2$. Tumors were harvested and either digested into a single-cell suspension for flow cytometry analysis or fixed in formaldehyde for immunohistochemistry (IHC) of mouse CD8 (1:300; Abcam, Cambridge, MA, USA) and mouse CD19 (1:300; Invitrogen, Waltham, MA, USA). The animal studies were conducted under protocols approved by the Ethics Committee of Fudan University Shanghai Cancer Center (ethic code: FUSCC-IACUC-S20210159, approved at 23 February 2021).

\subsection{Flow Cytometry and Antibodies}

Dead cells were excluded using Fixable Viability Dye eFluor780 (eBioscience, San Diego, CA, USA). Nonspecific staining was blocked using Fc Receptor Blocker (93, BD Biosciences). Intracytoplasmic staining and intranuclear transcriptional factor staining was performed according to the manufacturer's instructions (BD Biosciences). For intracellular CXCL13 and IL-21 staining, cells were stimulated with Leukocyte Activation Cocktail (BD Biosciences) for $6 \mathrm{~h}$. The following antibodies were used for the human specimens: anti-CD45 (HI30), anti-CD45RO (UCHL1), anti-CD4 (GK1.5), anti-CD25 (BC96), anti-CXCR5 (SPRCC5), antiPD1 (29F-1A12), anti-ICOS (C398.4A), anti-Foxp3 (259D/C7), anti-Bcl6 (K112-91), antiCXCL13 (53610), anti-IL-21 (3A3-N2.1), anti-CD8 (SK1), anti-CD19 (H), anti-CD20 (2H7), anti-B220 (RA3-6B2), anti-CD27 (0323), anti-CD38 (HIT2), anti-IgD (11-26c.2a), anti-CD138 (281-2), anti-IgG (QA19A42), and anti-IgM (MHM88). The following antibodies were used for the mouse specimens: anti-CD45 (30-F11), anti-CD4 (RM4-5), anti-CXCR5 (L138D7), anti-PD1 (29F.1A12), anti-ICOS (C398.4A), anti-CD8 (53-5.8), anti-B220 (RA3-6B2), and anti-CD138 (281-2). All antibodies were purchased from BD Bioscience and Biolegend (San Diego, CA, USA).

\section{Immunofluorescent Staining and Immunohistochemistry}

Paraffin-embedded formalin-fixed PDAC tumor tissue sections were cut into $5 \mu \mathrm{m}$ sections and processed for immunohistochemistry and immunofluorescent staining. For immunohistochemistry, human tumor sections were incubated with anti-CD4 (1:200, ab133616, Abcam), anti-CXCL13 (1:200, AF801, R\&D), anti-IL-21(1:200, ab5978, Abcam), anti-CD8 (1:300, ab237709, Abcam), and anti-CD20 (1:300, ab78237, Abcam) antibodies; mouse tumor sections were incubated with anti-CD8 (1:500, ab209775, Abcam), anti-CD20 (1:500, ab122788, Abcam), and anti-CD138 (1:200, ab181789, Abcam) antibodies. For immunofluorescence, human tumor sections were incubated with anti-CD4 (1:200, ab133616, Abcam), 
anti-CXCR5 (1:200, ab46218, Abcam), anti-PD-1 (1:200, ab53587, Abcam), anti-CXCL13 (1:50, AF801, R\&D), anti-IL-21(1:100, ab5978, Abcam), anti-CD8(1:500, ab237709, Abcam), and anti-CD20 (1:200, ab78237, Abcam) antibodies. Sections were visualized under a fluorescence microscope (NIKON ECLIPSE C1, Tokyo, Japan), and images were acquired using a digital camera (NIKON DS-U3). The tumor-infiltrating lymphocytes (TILs) in the immunohistochemistry and immunofluorescence analyses were defined as the lymphocytes inside the tumor.

\section{Cell Purification and Differentiation In Vitro}

$\mathrm{CD}^{+} \mathrm{T}$ cells, $\mathrm{CD}^{+} \mathrm{T}$ cells, and B cells were purified using isolation kits according to the manufacturer's protocols (STEMCELL Technologies, Vancouver, BC, Canada). For B cell maturation detection, Tfh cells $\left(\mathrm{CD} 4^{+} \mathrm{CD} 25^{-} \mathrm{CXCR}^{+} \mathrm{PD}-1^{+}\right)$and naive B cells $\left(\mathrm{CD} 19^{+}\right.$ $\mathrm{CD}^{-} \mathrm{IgD}^{+}$) were sorted using a FACSAria II flow cytometer (BD) and co-cultured at a ratio of 1:1 in serum-free $\mathrm{T}$ cell medium containing $1 \mu \mathrm{g} / \mathrm{mL}$ endotoxin-reduced staphylococcal enterotoxin B (SEB; Sigma, St. Louis, MO, USA). Cells were collected for cytokine detection on day 12. For the in vitro differentiation experiments, Tfh cells were stimulated using anti-CD3/CD28/CD2 antibodies (STEMCELL Technologies). For the chemotaxis assay, $\mathrm{CD}^{+} \mathrm{T}$ cells $\left(5 \times 10^{5}\right)$ and B cells $\left(5 \times 10^{5}\right)$ were seeded in a Transwell chamber $\left(3 \mu \mathrm{m}\right.$, Costar, Corning Inc., Corning, NY, USA), and Tfh cells $\left(1 \times 10^{6}\right)$ were seeded at the bottom of the chamber, with or without recombinant human (rh) CXCL13 (Abcam) or anti-CXCL13 neutralizing antibody (R\&D System, Minneapolis, MN, USA).

\section{Statistical Analysis}

Statistical analyses were performed using Prism software (version 6, GraphPad Software, Inc., La Jolla, CA, USA). Significant differences data between the two groups were compared using a Student's t-test. Overall survival (OS) and progression-free survival (PFS) of patients with PDAC were analyzed using the Kaplan-Meier method log-rank test. Data are presented as means \pm SDs. $p$-values $<0.05$ were considered to be statistically significant, and asterisks indicated the significance level of the $p$-value $\left({ }^{*} p<0.05,{ }^{* *} p<0.01\right.$, *** $p<0.001$ and ${ }^{* * * *} p<0.0001$ ) in the figures.

\section{Results}

6.1. Tumor-Infiltrating Tfh Cells Are Beneficial for the Prognosis of Patients with PDAC

To investigate the presence of Tfh cells in PDAC, lymphocytes from peripheral blood, spleen, and tumor tissue of patients with PDAC were separated and examined using flow cytometry. Immunosuppressive follicular regulatory T cells (Tfr cells) expressing CD25 and Foxp3 have co-expressed molecules with Tfh cells; therefore, we gated Tfh cells (CD4 ${ }^{+}$ $\mathrm{CXCR}^{+} \mathrm{PD}^{+}$) from CD4 ${ }^{+}$Foxp3 ${ }^{-}$cells (Figure S1A, Figure 1A). The individual difference in Tfh infiltration in tumor tissue was significantly stronger than that in peripheral blood and the spleen (Figure 1B,C). We then tested other characteristic molecules related to Tfh cells such as ICOS, Bcl6, CXCL13, and IL-21 (Figure 1D). Surface markers (PD1 and ICOS) had similar expression panels in tumors and spleens (Figure 1E), and significantly different expression levels of functional effectors (CXCL13 and IL-21) reflected the diverse status of tumor-infiltrating Tfh cells exposed to tumor antigens (Figure 1E). 
(A) Gated in $\mathrm{CD}^{+}{ }^{+}$Foxp3- cells
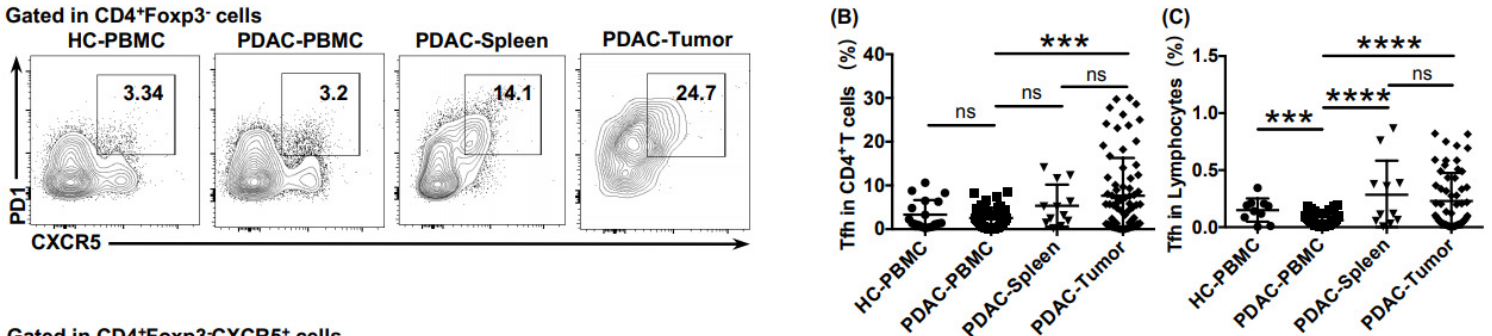

(D) Gated in $\mathrm{CD}^{+} \mathrm{Foxp} 3-\mathrm{CXCR} 5^{+}$cells
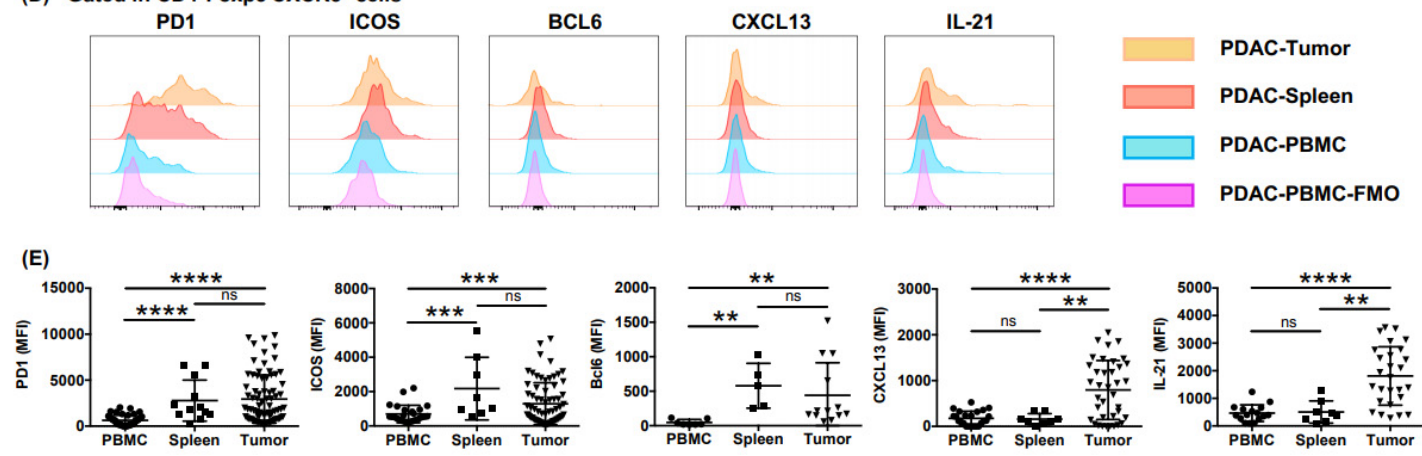

(F)
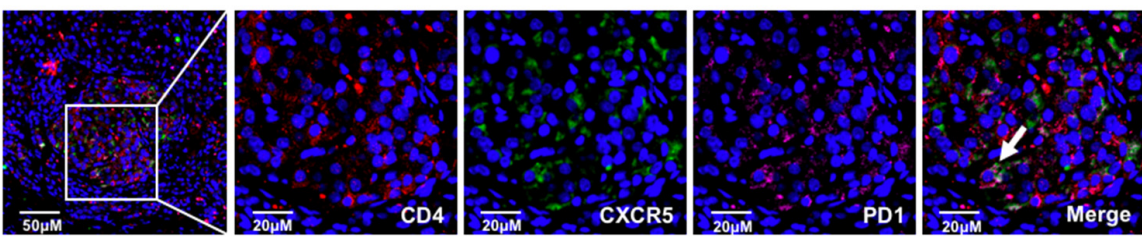

(G)
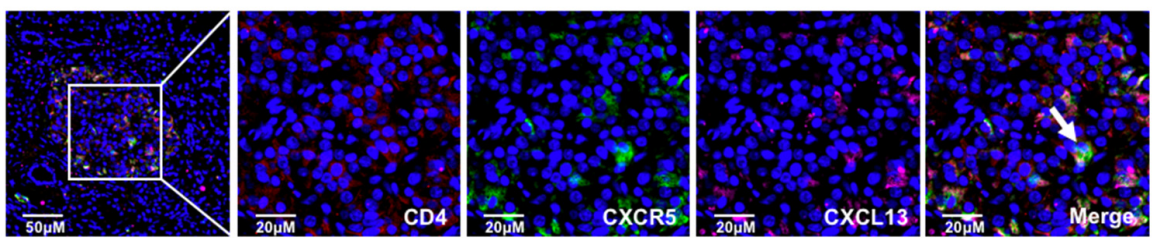

(H)
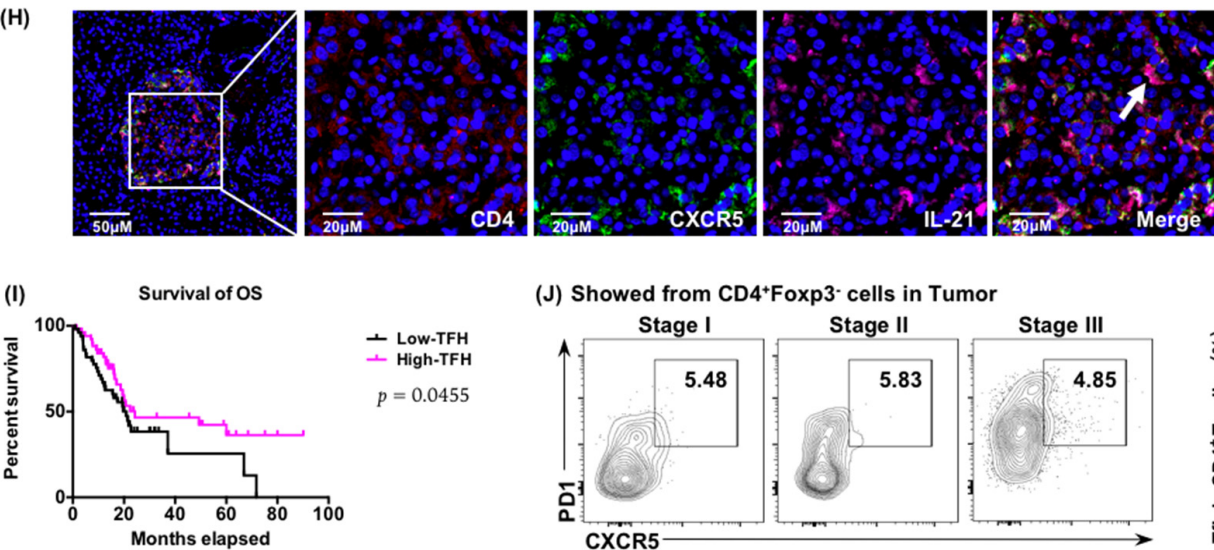

(J) Showed from CD4 ${ }^{+}$Foxp3 cells in Tumor
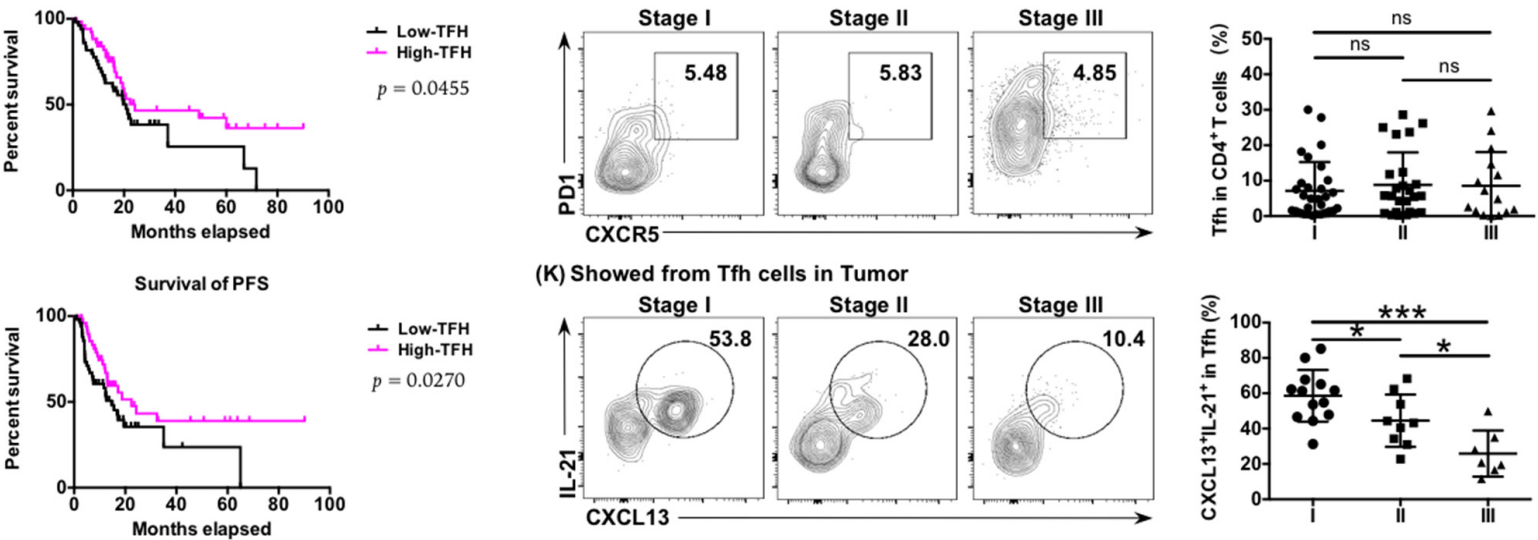

(K) Showed from Tfh cells in Tumor
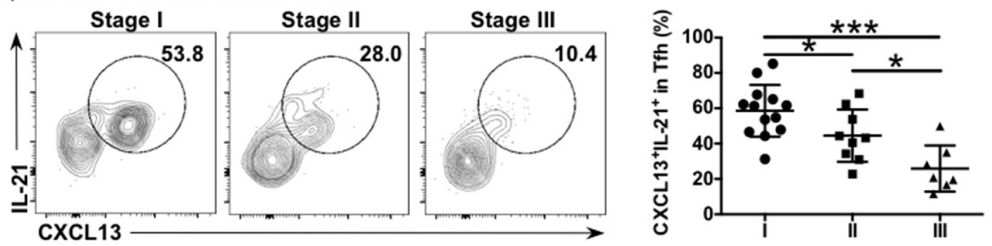

Figure 1. Tumor-infiltrating Tfh cells correlated positively with the prognosis of patients with PDAC. (A) Plots showing representative CXCR5 and PD1 surface staining of Tfh cells from peripheral blood (healthy donors and patients with PDAC), 
tumor tissue (patients with PDAC), and spleen (patients with PDAC). (B) Proportion of Tfh cells in CD4 ${ }^{+} \mathrm{T}_{\text {cells from }}$ peripheral blood (healthy donors, $n=18$; patients with PDAC, $n=45$ ), tumor tissue (patients with PDAC, $n=12$ ), and spleen (benign pancreatic cystic neoplasms, $n=69$ ). (C) Proportion of Tfh cells in lymphocytes from peripheral blood (healthy donors, $n=10$; patients with PDAC, $n=48$ ), tumor tissue (patients with PDAC, $n=11$ ), and spleen (benign pancreatic cystic neoplasms, $n=57$ ). (D) Representative histograms and (E) a statistical graph of the mean fluorescence intensity (MFI) of characteristic markers of Tfh cells from the peripheral blood, tumor tissues, and spleens of patients with PDAC. FMO: fluorescence minus one. (F-H) Representative immunofluorescence staining of total Tfh cells $\left(\mathrm{CD} 4^{+} \mathrm{CXCR} 5^{+} \mathrm{PD} 1^{+}\right)$and functional Tfh cells $\left(\mathrm{CD} 4^{+}\right.$CXCR5 ${ }^{+} \mathrm{CXCL}^{+} 3^{+}$and $\left.\mathrm{CD} 4^{+} \mathrm{CXCR} 5^{+} \mathrm{IL}-21^{+}\right)$in tumor tissues of PDAC. The samples were stained for CD4 (red), CXCR5 (green), PD1 (pink), CXCL13 (pink), IL-21 (pink), and DAPI (blue). Scale bars: 50 or $20 \mu \mathrm{m}$. (I) Kaplan-Meier survival curves for overall survival (OS) (left) and progression-free survival (PFS) (right) in patients with PDAC from the training cohort according to the functional Tfh cells (CD4 ${ }^{+}$CXCR5 ${ }^{+}$CXCL13 $\left.{ }^{+}\right)$density $(n=127, \log$-rank test and $p$ values are shown). (J) Representative flow cytometry data and the proportion of Tfh cells $\left(\mathrm{CD} 4^{+} \mathrm{CXCR} 5^{+} \mathrm{PD} 1^{+}\right)$ in $\mathrm{CD}^{+} \mathrm{T}$ cells in tumor tissue from patients with PDAC at different stages $\left(n_{I}=30, n_{I I}=25, n_{I I I}=15\right)$. (K) Representative flow cytometry data and the proportion of functional Tfh cells (CXCL13 ${ }^{+}$IL-21 $\left.{ }^{+}\right)$in Tfh cells in tumor tissue from patients with PDAC at different stages $\left(n_{I}=30, n_{I I}=25, n_{I I I}=15\right)$. Asterisks indicated the significance level of the $p$-value (ns: no significant difference, ${ }^{*} p<0.05,{ }^{* *} p<0.01,{ }^{* * *} p<0.001$ and $\left.{ }^{* * * *} p<0.0001\right)$.

The immunofluorescence results showed that the infiltration of Tfh cells in the tumor tissues of PDAC (Figure 1F-H), and in patients with high infiltration of functional Tfh cells $\left(\mathrm{CD}^{+} \mathrm{CXCR}^{+} \mathrm{CXCL13}{ }^{+}\right)$, resulted in longer OS and PFS (Figure 1I), indicating a positive correlation between functional infiltrating Tfh cells and patient survival. We further examined the relationship between functional infiltrating Tfh cells and the progression of PDAC. The expression of functional factors CXCL13 and IL-21 decreased gradually in higher tumor stages (Figure $1 \mathrm{~K}$ ), although the proportion of tumor-infiltrating Tfh cells among $\mathrm{CD}^{+} \mathrm{T}$ cells showed no significant reduction (Figure 1J), which suggested that the function of Tfh cells was impaired in the tumor microenvironment of PDAC.

\subsection{Tumor-Infiltrating Tfh Cells Were Related to $C D 8^{+} T$ Cell and B Cell Infiltration}

To explore the role of tumor-infiltrating Tfh cells, we examined the relationship between Tfh cells and other immune cells in PDAC tumor tissues. The immunohistochemistry results showed that the distribution of functional effectors CXCL13 and IL-21 of Tfh cells co-localized with CD8 ${ }^{+}$T cells and B cells (Figure 2A), and the immunofluorescence analysis showed that the $\mathrm{CD} 8^{+} \mathrm{T}$ cells (Figure $2 \mathrm{~B}$ ) and $\mathrm{CD} 20^{+} \mathrm{B}$ cells (Figure $2 \mathrm{D}$ ) were adjacent to functional Tfh cells $\left(\mathrm{CD}^{+} \mathrm{CXCL13^{+ }}\right)$. Moreover, there was a positive correlation between the infiltration of Tfh cells and $\mathrm{CD}^{+} \mathrm{T}$ cells (Figure $2 \mathrm{C}$ ). This was consistent with the analysis results from the public database [21], which showed that the infiltration of Tfh cells correlated strongly with the ratio of total $\mathrm{CD}^{+} \mathrm{T}$ cells and cytotoxic cells in TILs (Figure S2A). In addition, the infiltration of functional Tfh cells correlated positively with the distribution of $\mathrm{CD}_{2} 0^{+} \mathrm{B}$ cells (Figure 2D,E). Moreover, functional tumor-infiltrating Tfh cells $\left(\mathrm{CD}^{+} \mathrm{IL}^{-21^{+}}\right)$correlated positively with the infiltration of CD $138^{+}$plasma cells (Figure 2F,G). Taken together, these observations support a potential role for infiltrating Tfh cells in promoting anti-tumor immunity in PDAC. 
(A)

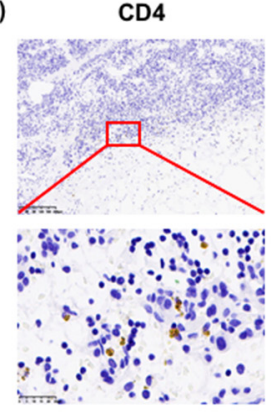

(B)

(D)
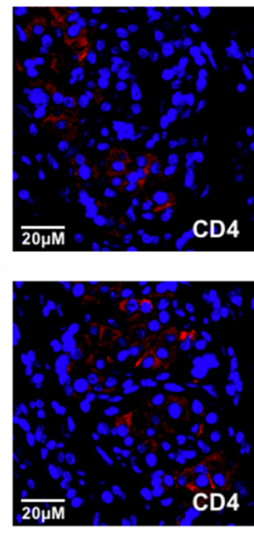

(F)
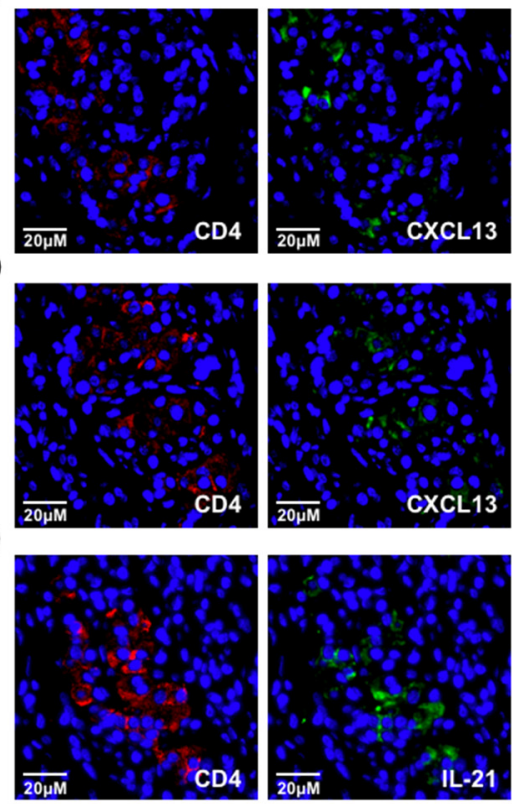

CXCL13
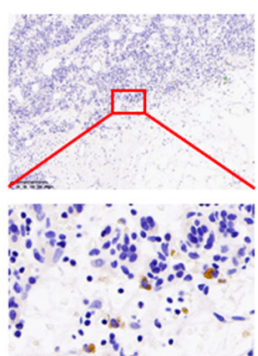

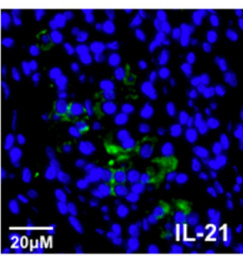

IL-21

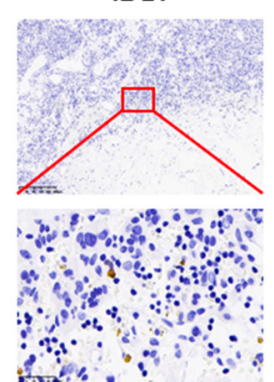

CD8

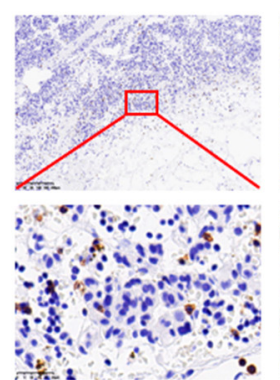

CD20

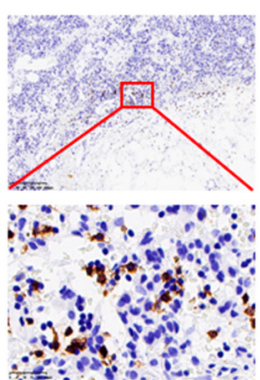

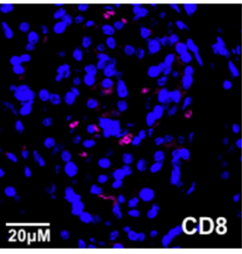
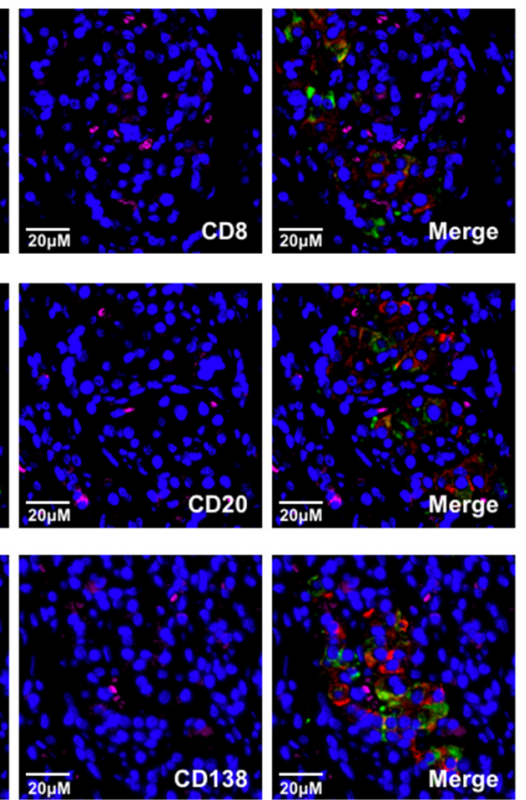

(C)

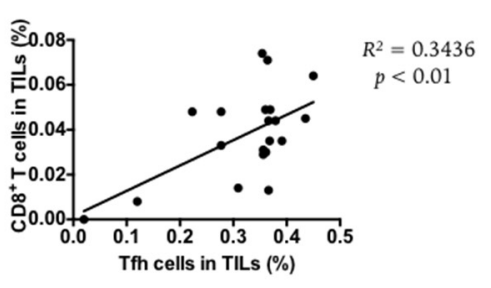

(E)

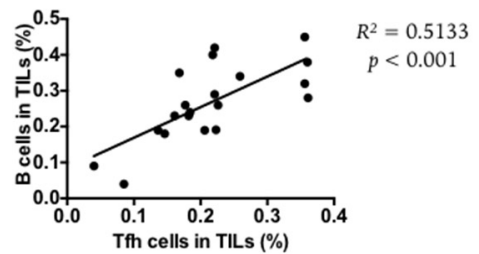

(G)

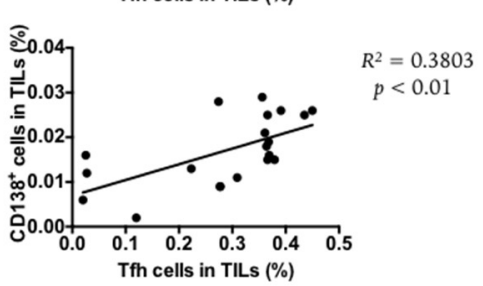

Figure 2. Tumor-infiltrating Tfh cells were related to $\mathrm{CD} 8^{+} \mathrm{T}$ cells and $\mathrm{B}$ cells infiltration. (A) Representative images of immunohistochemistry for $\mathrm{CD}^{+}, \mathrm{CXCL13} 3^{+}, \mathrm{IL}^{2}-21^{+}, \mathrm{CD}^{+}$, and $\mathrm{CD} 20^{+}$cells of continuous slices of tumor tissue from patients with PDAC. Scale bars: $200 \mu \mathrm{m}$ or $25 \mu \mathrm{m}$. (B) Representative images of the immunofluorescence of the colocalization of functional tumor-infiltrating Tfh cells $\left(\mathrm{CD}^{+} \mathrm{CXCL}_{13}{ }^{+}\right)$with $\mathrm{CD} 8^{+} \mathrm{T}$ cells. Scale bars: $20 \mu \mathrm{m}$. (C) Correlation between functional tumor-infiltrating Tfh cells $\left(\mathrm{CD} 4^{+} \mathrm{CXCL13}{ }^{+}\right)$with $\mathrm{CD} 8^{+} \mathrm{T}$ cells $(n=20)$. (D) Representative images of immunofluorescence of the co-localization of functional tumor-infiltrating Tfh cells $\left(\mathrm{CD} 4^{+}\right.$CXCL13 $\left.{ }^{+}\right)$with $\mathrm{CD} 20^{+} \mathrm{B}$ cells. Scale bars: $20 \mu \mathrm{m}$. (E) Correlation between functional tumor-infiltrating Tfh cells $\left(\mathrm{CD} 4^{+} \mathrm{CXCL} 13^{+}\right)$with $\mathrm{CD} 20^{+} \mathrm{B}$ cells $(n=20)$. (F) Representative images of the immunofluorescence of the co-localization of functional tumor-infiltrating Tfh cells $\left(\mathrm{CD} 4^{+} \mathrm{IL}-21^{+}\right)$with $\mathrm{CD} 138^{+}$plasma cells. Scale bars: $20 \mu \mathrm{m}$. (G) Correlation between functional tumor-infiltrating Tfh cells $\left(\mathrm{CD} 4^{+} \mathrm{IL}-21^{+}\right)$and $\mathrm{CD} 138^{+}$plasma cells $(n=20)$.

\subsection{Tfh Cells Mediated Anti-Tumor Cellular Immunity and Humoral Immunity, Which Was Impaired in PDAC}

To further explore the potential anti-tumor role of Tfh cells in PDAC, we detected the function of circulating Tfh cells (cTfh cells) in the peripheral blood of healthy donors and patients with PDAC. Compared with that in healthy donors, the ability of cTfh cells to express effector factors CXCL13 and IL-21 in patients with PDAC was significantly impaired and was further impaired in higher tumor stages (Figure $3 \mathrm{~A}$ ). To verify the effect of CXCL13 secreted by Tfh cells on CD8 ${ }^{+} \mathrm{T}$ cells and B cells, cTfh cells (CD45RO ${ }^{-}$ $\mathrm{CD}^{+} \mathrm{CD}^{2} 5^{-} \mathrm{CXCR}^{+} \mathrm{PD}-1^{+}$) from healthy donors and patients with PDAC were sorted using flow cytometry. After amplification in vitro, Tfh cells with or without rhCXCL13 or anti-CXCL13 neutralizing antibody were added to the bottom of Transwell chambers of control group and experimental groups, and $\mathrm{CD} 8^{+} \mathrm{T}$ cells and $\mathrm{B}$ cells isolated from the 
peripheral blood of healthy donors were seeded in the top of the Transwell chambers of three groups at a ratio of 1:1. After $24 \mathrm{~h}$, the percentage of $\mathrm{CD} 8^{+} \mathrm{T}$ cells and $\mathrm{B}$ cells in the bottom of the wells were detected. Whether in PDAC patients or healthy donors, the recruitment of $\mathrm{CD} 8^{+} \mathrm{T}$ cells and $\mathrm{B}$ cells significantly increased when treated with rhCXCL13 and was almost blocked when treated with anti-CXCL13 antibodies (Figure 3B,C), proving the crucial role of CXCL13 in recruiting CD8 ${ }^{+} \mathrm{T}$ cells and B cells. Notably, chemotaxis was significantly decreased in cells from PDAC patients compared with those from healthy donors, whether in vehicle conditions or when treated with rhCXCL13 (Figure S3C), and rhCXCL13 treatment roughly raised the recruitment level of CD8 ${ }^{+} \mathrm{T}$ cells and $\mathrm{B}$ cells of PDAC to the level of the untreated healthy control (Figure 3B,C). This indicated an impaired function of Tfh cells in PDAC, explaining why there were not many $\mathrm{CD}^{+} \mathrm{T}$ cells adjacent to functional Tfh cells $\left(\mathrm{CD} 4^{+}\right.$CXCL13 $\left.{ }^{+}\right)$in Figure 2.

Additionally, we found that the proportions of total plasma cells $\left(\mathrm{CD} 19^{+} \mathrm{CD} 20^{+}\right.$ $\mathrm{CD}^{+} 7^{+} \mathrm{CD} 38^{+}$) (Figure 3D) and of those secreting IgG (Figure 3E) and IgM (Figure 3F) in PDAC were significantly lower than those in the healthy donors, which gradually decreased in higher tumor stages. We further detected the auxiliary role of Tfh cells on B cell maturation by co-culturing cTfh cells from healthy donors or patients with PDAC with heterologous naive $\mathrm{B}$ cells $\left(\mathrm{CD} 19^{+} \mathrm{CD} 27^{-} \mathrm{IgD}^{+}\right)$at a ratio of $1: 1$, respectively. After 12 days, the proportions of total plasma cells (Figure 3G) and of those secreting IgG (Figure 3H) and IgM (Figure 3I) in B cells co-cultured with cTfh cells from patients with PDAC were significantly lower than those from the healthy donors, indicating the impaired auxiliary effect of Tfh cells on B cell maturation.

Taken together, these results indicated that $\mathrm{Tfh}$ cells induced the chemotaxis of $\mathrm{CD} 8^{+} \mathrm{T}$ cells and B cells by secreting the chemokine CXCL13 and promoted the maturation of B cells into plasma cells, which produced tumor antigen-specific antibodies, thereby enhancing PDAC impaired anti-tumor cellular immunity and anti-tumor humoral immunity.

(A) Gated in Tfh cells in PBMC
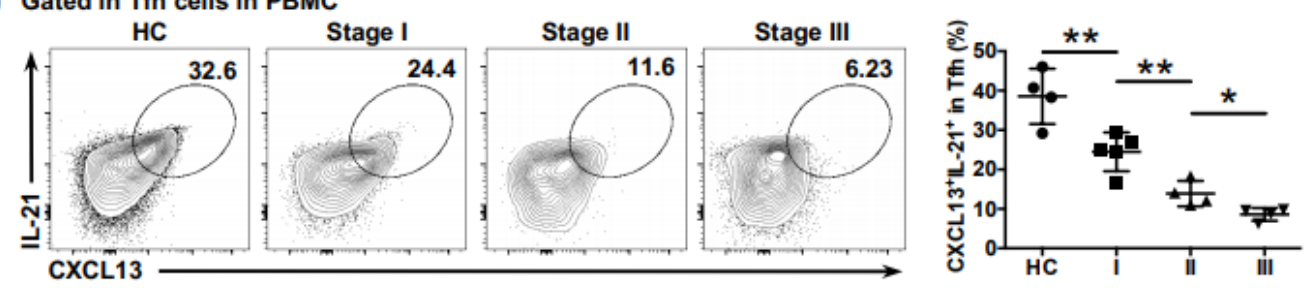

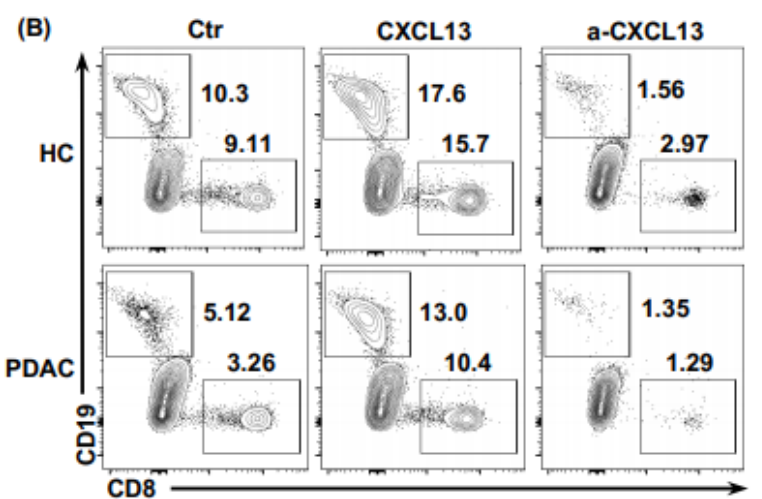

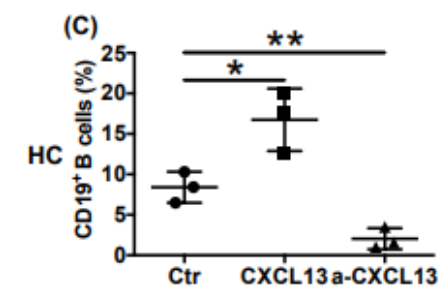
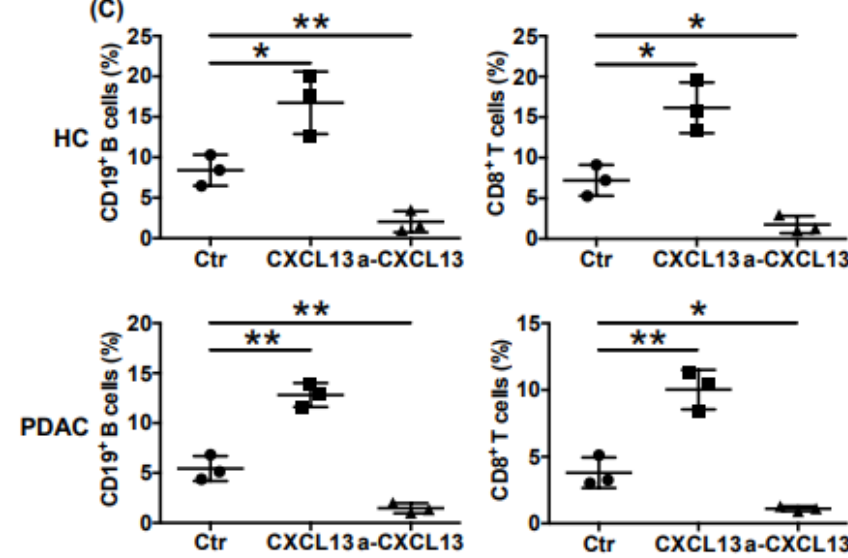

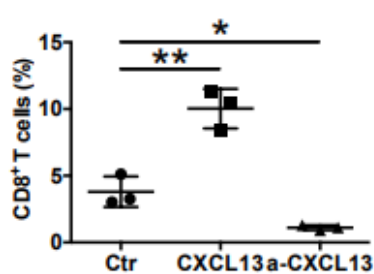

Figure 3. Cont. 
(D) Gated in $\mathrm{CD} 19^{+} \mathrm{CD} 20^{+}$cells in PBMC
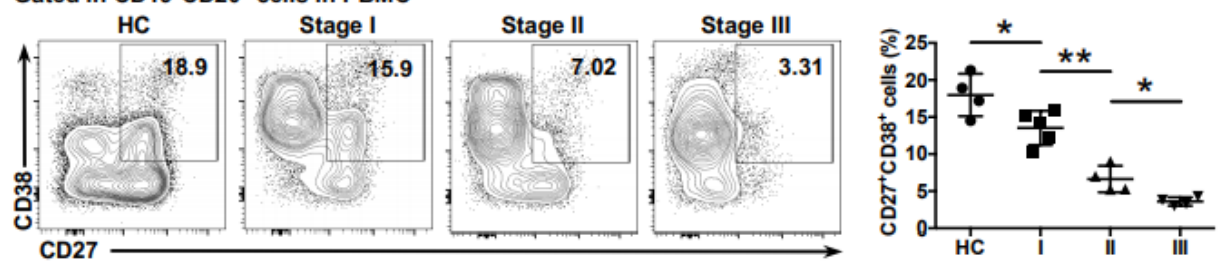

(E) Gated in $\mathrm{CD} 27^{+} \mathrm{CD} 38^{+}$cells in PBMC (IgG)

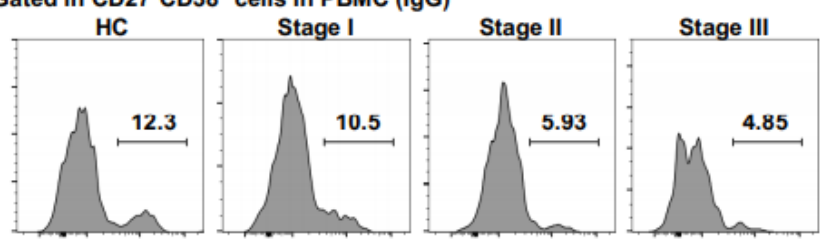

(F) Gated in $\mathrm{CD}^{+} 7^{+} \mathrm{CD} 38^{+}$cells in PBMC (IgM)
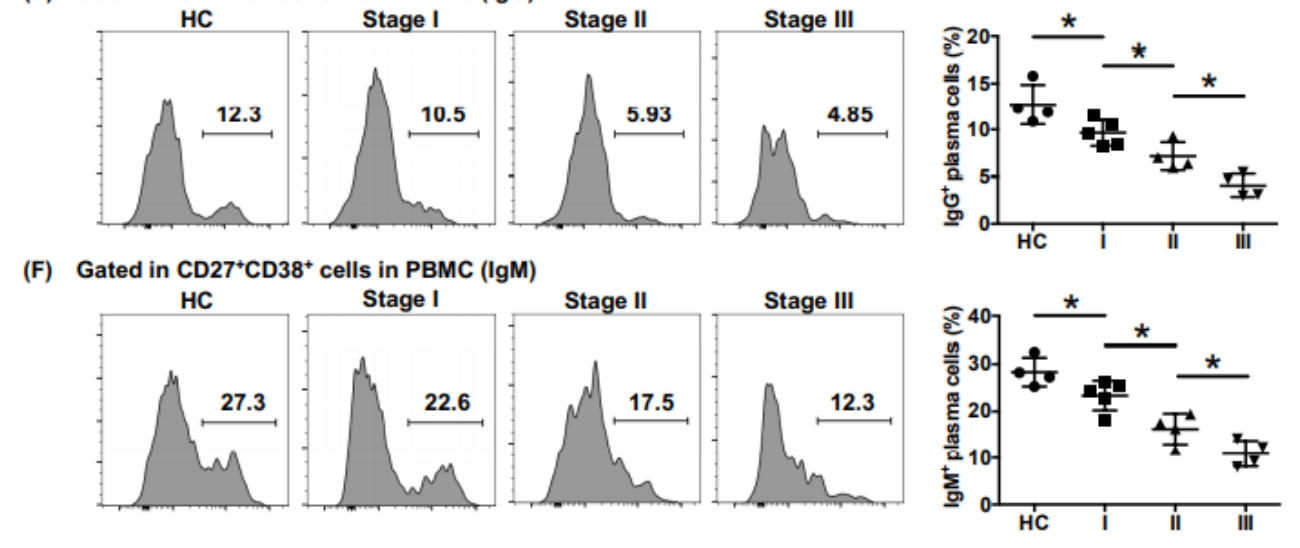

(G) Gated in $\mathrm{CD} 19^{+} \mathrm{CD} 20^{+}$cells in PBMC
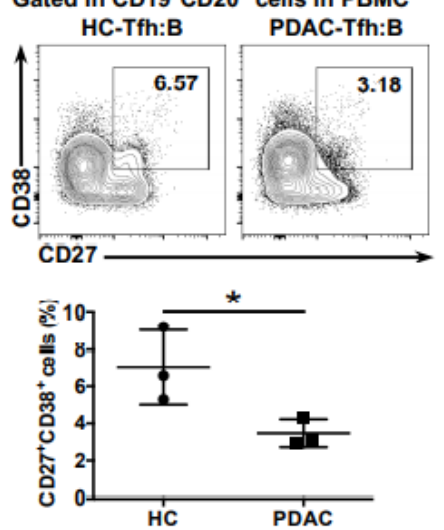

(H) Gated in $\mathrm{CD}^{+} 7^{+} \mathrm{CD} 38^{+}$cells in PBMC (IgG)
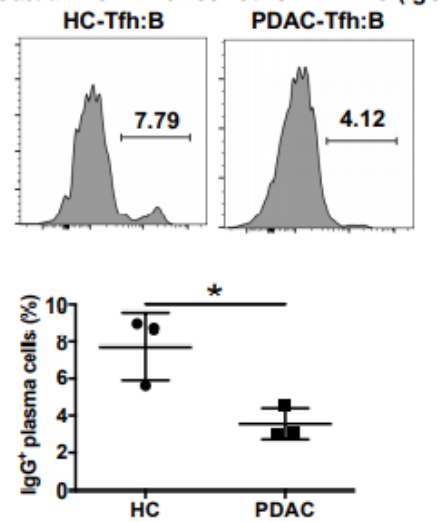

(I) Gated in $\mathrm{CD}_{2} 7^{+} \mathrm{CD} 38^{+}$cells in PBMC (IgM)
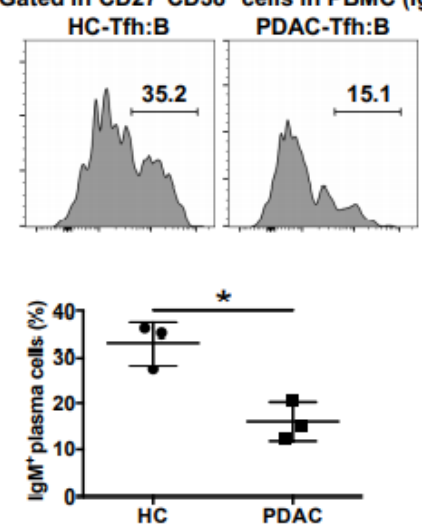

Figure 3. The anti-tumor function of Tfh cells was impaired in PDAC. (A) Representative flow cytometry data and the proportion of functional cTfh cells $\left(\mathrm{CXCL} 13^{+} \mathrm{IL}-21^{+}\right)$from the peripheral blood of healthy donors $(n=4)$ and patients with PDAC of different stages $\left(n_{I}=5, n_{I I}=4, n_{I I I}=4\right)$. (B) Representative flow cytometry data and $(\mathrm{C})$ the proportion of CD8 ${ }^{+}$ $\mathrm{T}$ cells and B cells recruited to the bottom of the Transwell chamber by cTfh cells treated with or without rhCXCL13 or anti-CXCL13 neutralizing antibodies. (D) Representative flow cytometry data and the proportion of plasma cells $\left(C D 27^{+}\right.$ $\left.\mathrm{CD} 38^{+}\right)$in B cells $\left(\mathrm{CD} 19^{+} \mathrm{CD} 20^{+}\right)$from the peripheral blood of healthy donors $(n=4)$ and patients with PDAC at different stages $\left(n_{I}=5, n_{I I}=4, n_{I I I}=4\right)$. (E) Representative flow cytometry data and the proportion of IgG-secreting plasma cells from cells in (D). (F) Representative flow cytometry data and the proportion of IgM-secreting plasma cells from cells in (D). (G) Representative flow cytometry data and the proportion of plasma cells $\left(\mathrm{CD} 27^{+} \mathrm{CD} 38^{+}\right)$in B cells $\left(\mathrm{CD} 19^{+} \mathrm{CD} 20^{+}\right)$ co-cultured with cTfh cells sorted from the peripheral blood of healthy donors $(n=3)$ and patients with PDAC $(n=3)$. (H) Representative flow cytometry data and the proportion of IgG-secreting plasma cells from cells in (G). (I) Representative flow cytometry data and the proportion of IgM-secreting plasma cells from cells in (G). Asterisks indicated the significance level of the $p$-value ${ }^{*} p<0.05$ and $\left.{ }^{* *} p<0.01\right)$.

\subsection{The Impaired Function of Tfh Cells Was Mediated by PD-L1/PD-1 Signaling in PDAC}

Tfh cells show persistently high expression of PD-1 on their surface, which is one of the characteristics that differentiates Tfh cells from other subtypes of $\mathrm{CD} 4^{+} \mathrm{T}$ cells. Considering that elevated PD-L1 expression correlates with poor prognosis in PDAC [22], we hypothesized that the function of Tfh cells would be inhibited by the abundant PDL1/-PD1 signaling in the PDAC tumor environment. The ability of cTfh cells cultured 
in vitro to express CXCL13 and IL-21 was significantly enhanced when treated with antiPD-1 antibodies and significantly inhibited by treatment with rhPD-L1, whether from healthy donors or patients with PDAC (Figure 4A). A similar trend was also observed in the ability of cTfh cells to recruit CD8 ${ }^{+} \mathrm{T}$ cells and B cells (Figure $4 \mathrm{~B}, \mathrm{C}$ ), as well as to help B cells mature into plasma cells and produce antibodies in the Tfh:B cell co-culture system (Figure 4D-F). These results indicated that the function of Tfh cells was inhibited by PD-L1/PD-1 signaling, thereby mediating immunosuppression in PDAC.

\subsection{Ectopic Tfh Cells Shaped the Immunoactive Tumor Microenvironment in Mouse Models of PDAC}

To accurately simulate the role of Tfh cells in the tumor microenvironment, we established a subcutaneous mouse model of PDAC. Every three days, PBS, rmCXCL13, rmIL-21, or Tfh cells isolated from the spleen of pancreatic cancer mice by flow cytometry were intravenously injected into tumor-bearing mice in the control group and three experimental groups, respectively. Compared with that of the PBS group, the tumor growth of the other groups was significantly inhibited, with no significant difference in weight when euthanized (Figure 5A). The results of immunohistochemistry and flow cytometry showed significantly more infiltration of CD8 ${ }^{+} \mathrm{T}$ cells and $\mathrm{B}$ cells in the rmCXCL13 group than in the PBS group (Figure 5B,C). Meanwhile, the proportion of CD138 $8^{+}$plasma cells in the rmIL-21 group and Tfh cells group was significantly higher than in the PBS group (Figure 5D). The above results revealed the role of CXCL13 in CD8 ${ }^{+} \mathrm{T}$ cell and B cell recruitment, and IL-21 in B cell maturation, which further proved that Tfh cells help to shape the immunoactive tumor microenvironment, thereby exerting anti-tumor effects in PDAC.

(A)

CXCL13+LL-21+ in CD4+CXCR5+PD1+ in PBMC
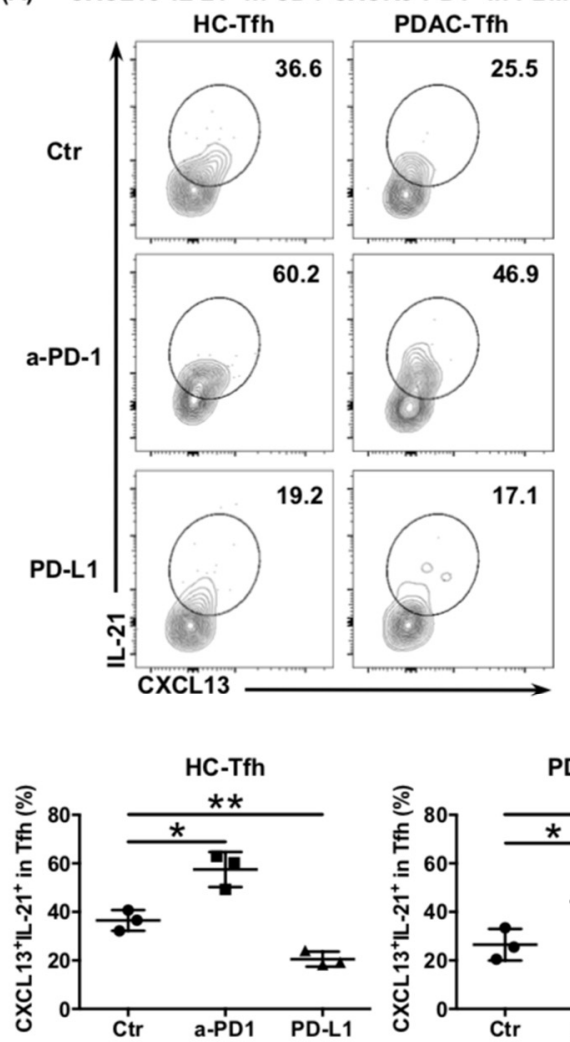

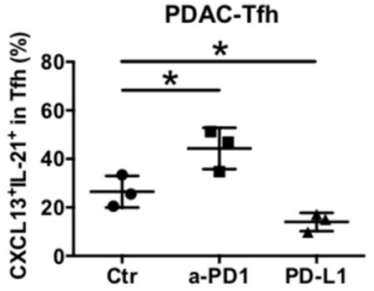

(B)

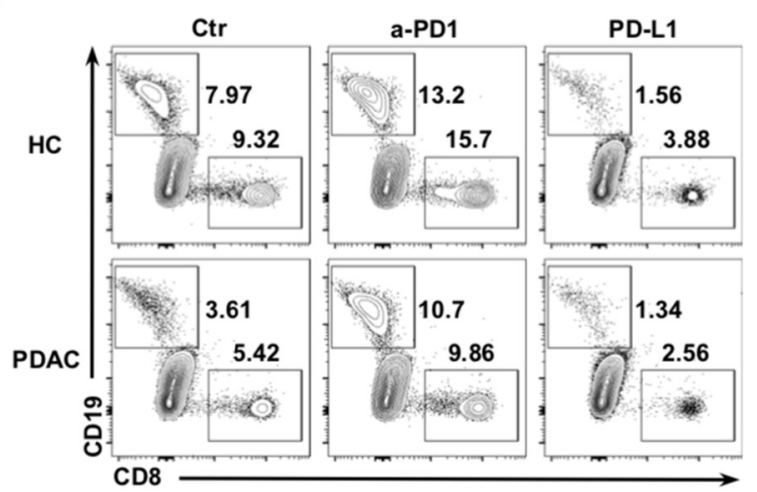

(C)
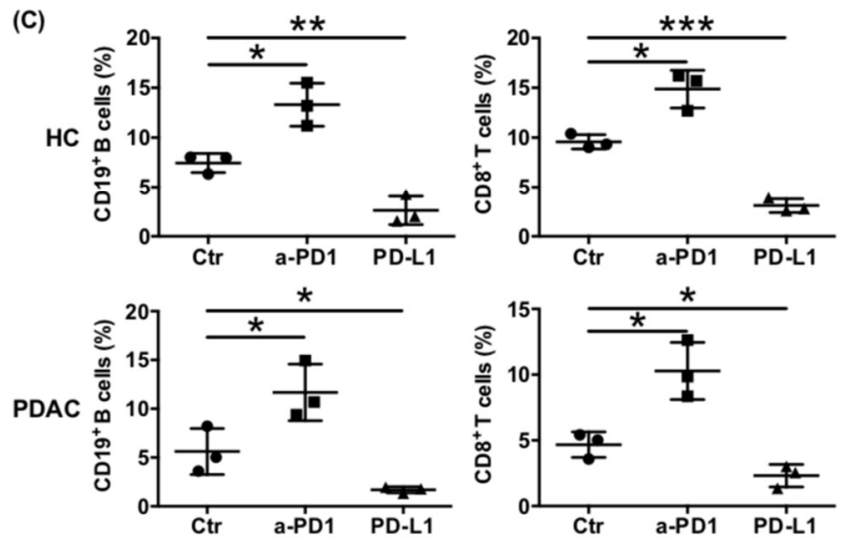

Figure 4. Cont. 
(D) Gated in $\mathrm{CD} 19^{+} \mathrm{CD} 20^{+}$cells in PBMC

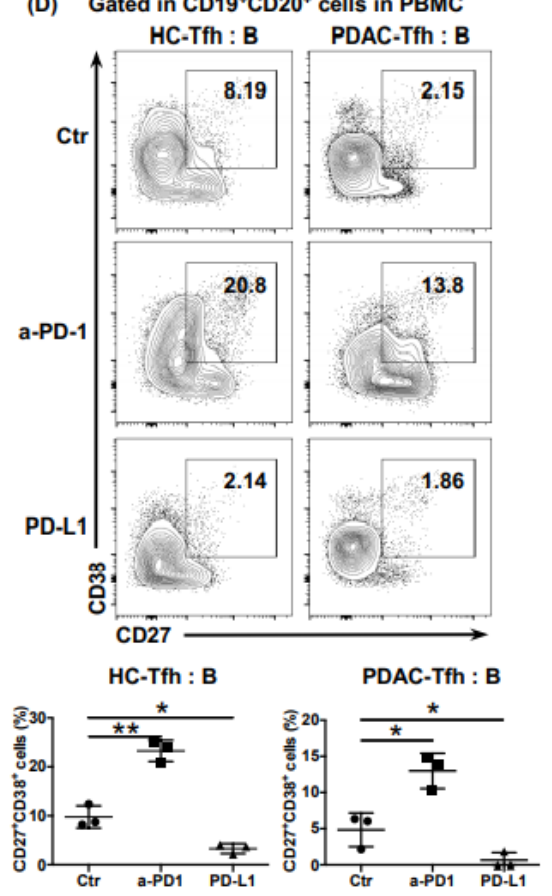

(E) Gated in CD27+CD38+ cells in PBMC (IgG)

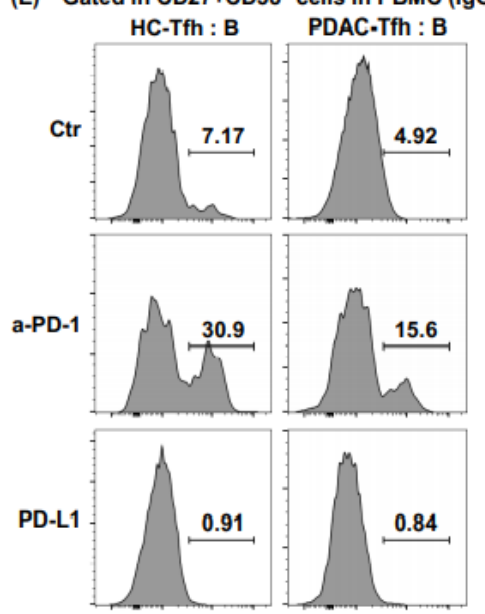

HC-Tfh : B

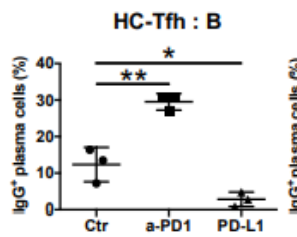

PDAC-Tfh : B

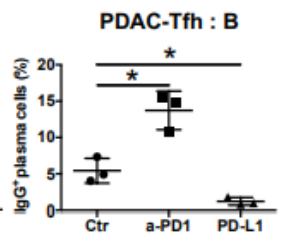

(F) Gated in $\mathrm{CD}_{2} 7^{+} \mathrm{CD} 38^{+}$cells in PBMC (IgM)
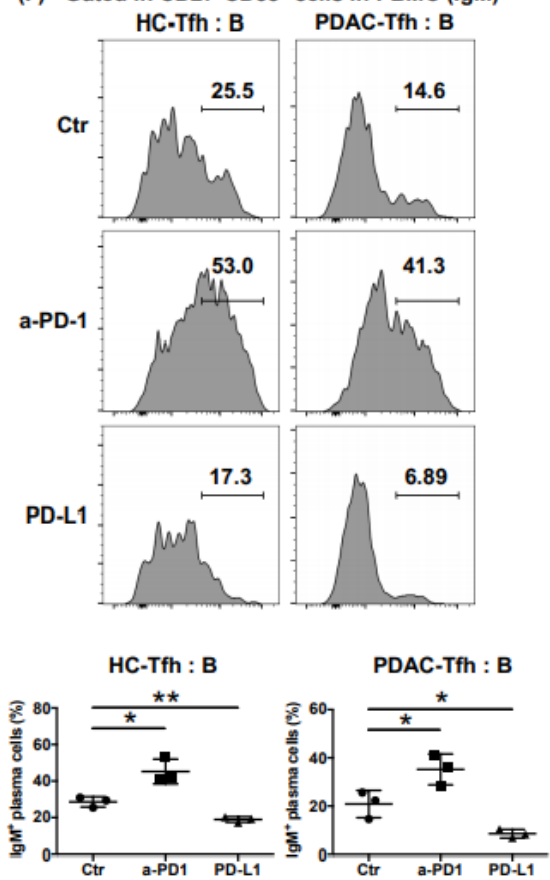

Figure 4. PD-L1/PD-1 signaling inhibits Tfh function and mediates immune escape of PDAC. (A) Representative flow cytometry data and the proportion of functional cTfh cells $\left(\mathrm{CD} 4^{+}\right.$CXCR5 $\left.{ }^{+} \mathrm{PD}^{+} \mathrm{CXCL} 13^{+} \mathrm{IL}-21^{+}\right)$cultured in in vitro with or without anti-PD1 or rhPD-L1 from the peripheral blood of healthy donors $(n=4)$ and patients with PDAC $(n=4)$. (B) Representative flow cytometry data and (C) the proportion of CD8 ${ }^{+} \mathrm{T}$ cells and B cells recruited to the bottom of the Transwell chamber by cTfh cells, treated with or without anti-PD1 or rhPD-L1 from the peripheral blood of healthy donors $(n=4)$ and patients with PDAC $(n=4)$. (D) Representative flow cytometry data and the proportion of plasma cells $\left(\mathrm{CD} 27^{+} \mathrm{CD} 38^{+}\right)$in B cells $\left(\mathrm{CD} 19^{+} \mathrm{CD} 20^{+}\right)$co-cultured with cTfh cells, treated with or without anti-PD1 or rhPD-L1 from the peripheral blood of healthy donors $(n=3)$ and patients with PDAC $(n=3)$. (E) Representative flow cytometry data and the proportion of IgG-secreting plasma cells from the cells in (D). (F) Representative flow cytometry data and the proportion of IgM-secreting plasma cells from the cells in (D). Asterisks indicated the significance level of the $p$-value $\left({ }^{*} p<0.05,{ }^{* *} p<0.01\right.$ and $\left.{ }^{* * *} p<0.001\right)$.

\subsection{Neoadjuvant Chemotherapy Reversed the Dysfunction of Tfh Cells}

Considering the poor responsiveness of PDAC to immunotherapy, we speculated whether neoadjuvant chemotherapy would ameliorate the anti-tumor function of Tfh cells, thereby increasing the immune activity of the PDAC microenvironment. Samples from patients who had received four cycles of neoadjuvant AG (nab-paclitaxel + gemcitabine) before surgery were obtained. The levels of CXCL13 and IL-21 expressed by tumor-infiltrating Tfh cells in patients who received neoadjuvant chemotherapy was higher than those in patients who had not (Figure 6B), although the proportion of Tfh cells showed no obvious difference (Figure 6A). The ability of cTfh cells to express CXCL13 and IL-21 was enhanced significantly after receiving neoadjuvant chemotherapy (Figure 6D), with the proportion of cTfh cells showing no obvious increase (Figure 6C). A chemotaxis assay demonstrated an enhanced ability of cTfh cells after chemotherapy to recruit CD8 ${ }^{+} \mathrm{T}$ cells and B cells (Figure 6E). Consistently, the proportions of total plasma cells and of those secreting IgG and IgM increased significantly after chemotherapy, whether in B cells from peripheral blood (Figure $6 \mathrm{~F}-\mathrm{H}$ ) or in those co-cultured with the Tfh cells of patients (Figure 6I-K), showing a reversal of the function of Tfh cells after neoadjuvant chemotherapy. 
(A)
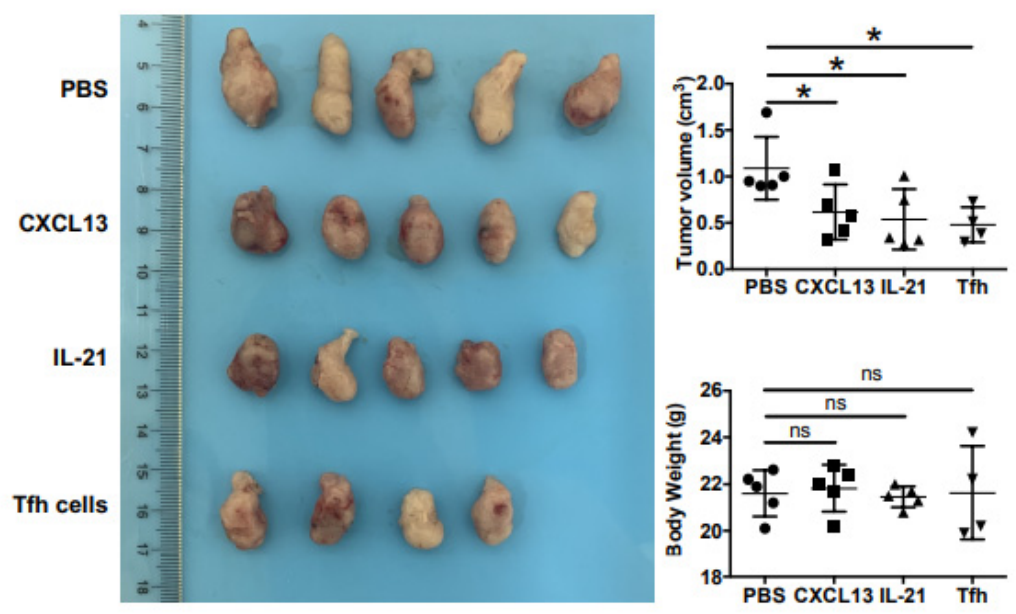

(B)

CD8

CD19

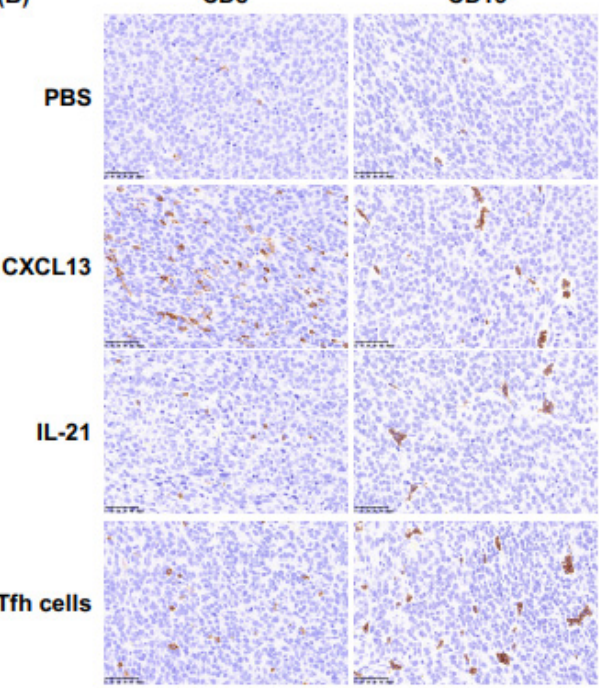

(C)
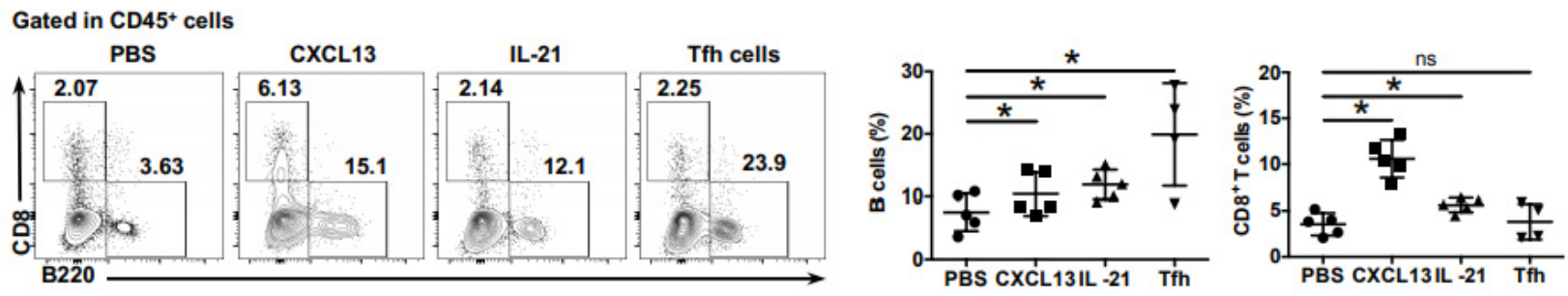

(D) Gated in $\mathrm{CD}^{+} 5^{+} \mathrm{B}_{220^{+}}$cells
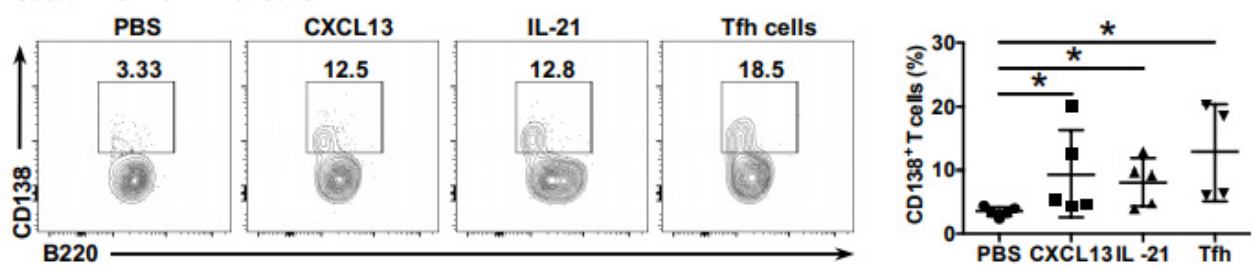

Figure 5. Tfh cells shape the immunoactive tumor microenvironment in a PDAC mouse model. (A) Resected tumors and tumor volumes in the subcutaneous PDAC mouse model treated with injection of PBS $(n=5)$, rmCXCL13 $(n=5)$, rmIL-21 $(n=5)$, or Tfh cells $(n=4)$, separately. (B) Representative images of immunohistochemistry of CD8 ${ }^{+} \mathrm{T}$ cells and CD20 $0^{+} \mathrm{B}$ cells of tumor tissues of tumor-bearing mice. Scale bars: $50 \mu \mathrm{m}(\mathrm{C})$ Representative flow cytometry data and the proportions of CD8 ${ }^{+} \mathrm{T}$ cells and B cells in the lymphocytes of tumor tissues of tumor-bearing mice. (D) Representative flow cytometry data and the proportions of $\mathrm{CD}_{138^{+}}$plasma cells in the lymphocytes of tumor tissues of tumor-bearing mice. Asterisks indicated the significance level of the $p$-value (ns: no significant difference, ${ }^{*} p<0.05$ ). 
(A) Gated in CD4+Foxp3- cells in Tumor

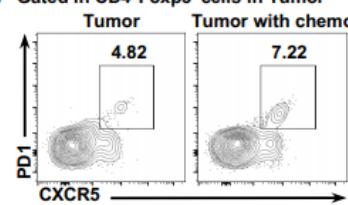

(C) Gated in $\mathrm{CD}^{+}{ }^{+}$Foxp3- cells in PBMC

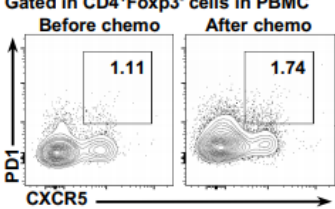

(E)

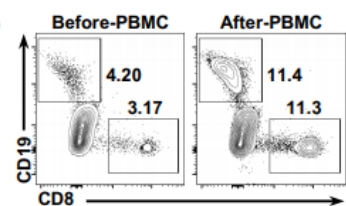

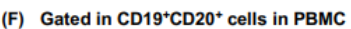

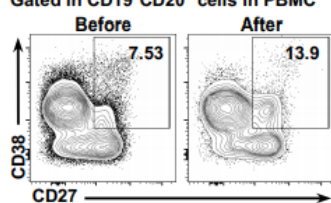

(G) Gated in CD27+CD38+ cells in PBMC (IgG)

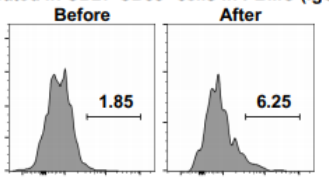

(H) Gated in $\mathrm{CD}^{2} 7^{+} \mathrm{CD} 38^{+}$cells in PBMC (IgM)

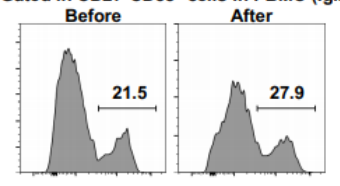

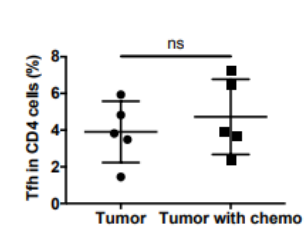

(B)
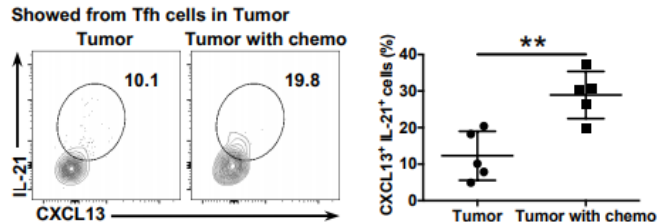

(D) Showed from Th cells in PBMC
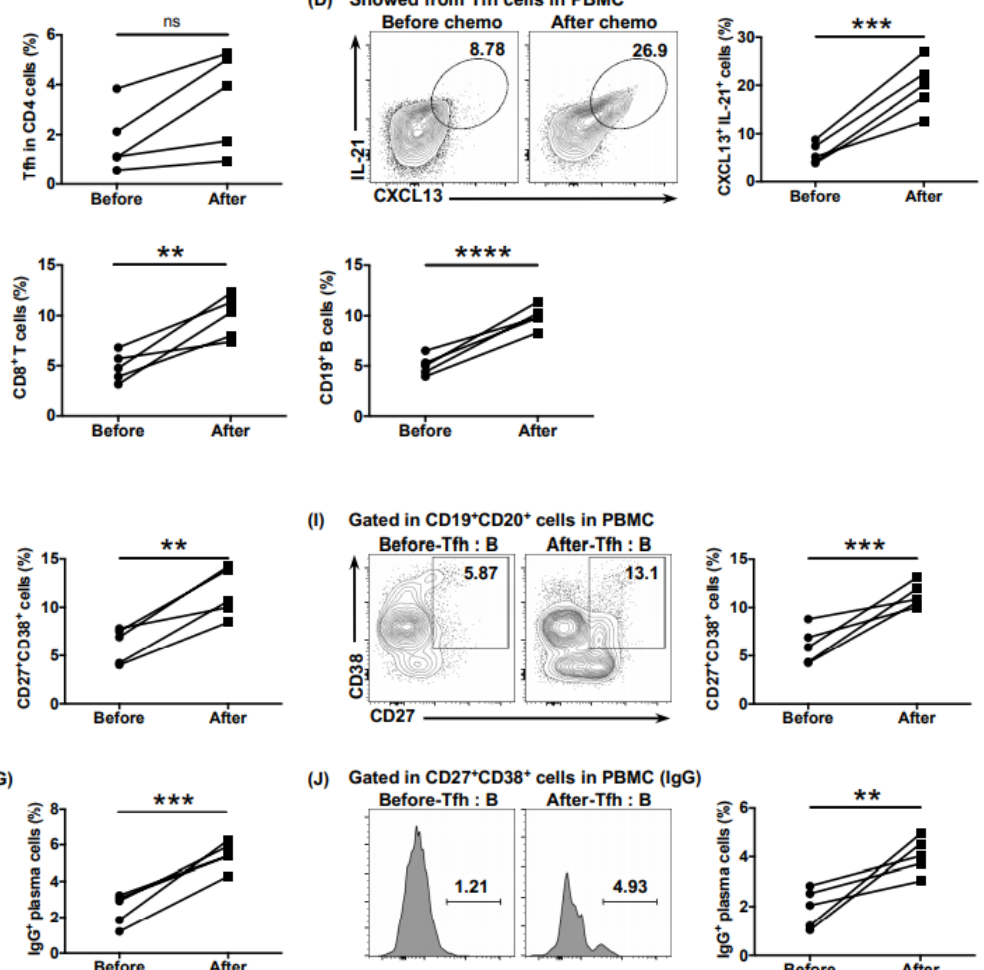

(J)
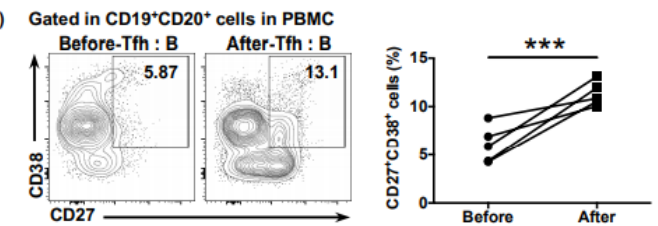

(J) Gated in $\mathrm{CD}_{2} 7^{+} \mathrm{CD} 38^{+}$cells in PBMC (IgG)
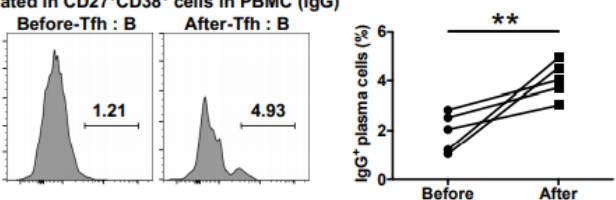

(K) Gated in $\mathrm{CD}_{27}{ }^{+} \mathrm{CD} 38^{+}$cells in PBMC (IgM)
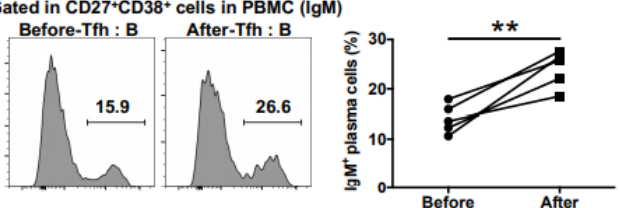

Figure 6. Neoadjuvant chemotherapy rescues the impaired function of Th cells. (A) Representative flow cytometry data and the proportion of total tumor-infiltrating Tfh cells $\left(\mathrm{CD} 4^{+} \mathrm{CXCR} 5^{+} \mathrm{PD} 1^{+}\right)$from the tumor tissues of patients with PDAC with $(n=5)$ or without $(n=5)$ neoadjuvant chemotherapy. (B) Representative flow cytometry data and the proportion of functional tumor-infiltrating Tfh cells (CXCL13 $\left.{ }^{+} \mathrm{IL}-21^{+}\right)$from the tumor tissues of patients with PDAC with $(n=5)$ or without $(n=5)$ neoadjuvant chemotherapy. (C) Representative flow cytometry data and (F) the proportion of total cTfh cells $\left(\mathrm{CD} 4^{+} \mathrm{CXCR} 5^{+}\right.$ $\left.\mathrm{PD}^{+}\right)$from the peripheral blood of patients with PDAC $(n=5)$ before or after receiving neoadjuvant chemotherapy. (D) Representative flow cytometry data and $(\mathbf{H})$ the proportion of functional cTfh cells $\left(\mathrm{CXCL13}{ }^{+} \mathrm{IL}-21^{+}\right)$from the peripheral blood of patients with PDAC $(n=5)$ before or after receiving neoadjuvant chemotherapy. (E) Representative flow cytometry data and the proportion of $\mathrm{CD} 8^{+} \mathrm{T}$ cells and $\mathrm{B}$ cells recruited to the bottom of the Transwell chamber by the cTfh cells of patients with PDAC $(n=5)$ before or after receiving neoadjuvant chemotherapy. (F) Representative flow cytometry data and the proportion of plasma cells $\left(\mathrm{CD} 27^{+} \mathrm{CD} 38^{+}\right)$in $\mathrm{B}$ cells $\left(\mathrm{CD} 19^{+} \mathrm{CD} 20^{+}\right)$from the peripheral blood of patients with PDAC ( $n=5)$ before or after receiving neoadjuvant chemotherapy. (G) Representative flow cytometry data and the proportion of IgG-secreting plasma cells from the cells in (F). (H) Representative flow cytometry data and the proportion of IgM-secreting plasma cells from the cells in (F). (I) Representative flow cytometry data and the proportion of plasma cells $\left(\mathrm{CD} 27^{+} \mathrm{CD} 38^{+}\right)$in B cells $\left(\mathrm{CD} 19^{+} \mathrm{CD} 20^{+}\right)$co-cultured with cTfh cells sorted from the peripheral blood of patients with PDAC $(n=5)$ before or after receiving neoadjuvant chemotherapy. (J) Representative flow cytometry data and the proportion of IgG-secreting plasma cells from the cells in (I). (K) Representative flow cytometry data and the proportion of IgM-secreting plasma cells from the cells in (I). Asterisks indicated the significance level of the $p$-value (ns: no significant difference, ${ }^{* *} p<0.01,{ }^{* * *} p<0.001$ and $\left.{ }^{* * * *} p<0.0001\right)$. 


\section{Discussion}

For a long time, $\mathrm{CD} 8^{+} \mathrm{T}$ cells and NK cells have been considered the main force in killing tumor cells $[23,24]$; however, research has shown that, without sufficient assistance from $\mathrm{CD}^{+} \mathrm{T}$ cells, $\mathrm{CD} 8^{+} \mathrm{T}$ cells cannot reach their full potential, emphasizing the irreplaceable role of $\mathrm{CD}^{+} \mathrm{T}$ cells in anti-tumor immunity $[25,26]$. As a subgroup of $\mathrm{CD} 4^{+} \mathrm{T}$ cells, Tfh cells can assist in B cell differentiation and maturation and promote the production of antigen-specific antibodies [12]. In the past decade, Tfh cells have been extensively studied in the anti-infective immune response and in autoimmune diseases [14]. However, the most exciting discovery is the anti-tumor effects of Tfh cells in malignant tumors, including breast cancer, colorectal cancer, hepatocellular carcinoma, and non-small cell lung cancer [14-18]. In the present study, we revealed that Tfh cells indeed existed in the tumor tissues of PDAC, in which they remodel the anti-tumor microenvironment and correlate with tumor stages and better patient prognosis.

Recently, the role of CXCL13 in shaping the immunoactive tumor microenvironment has been confirmed [27-30]. In the study of Bai et al. [31], CD8 ${ }^{+} \mathrm{CXCR} 5^{+} \mathrm{T}$ cells were identified as a potent subset of $\mathrm{CD}^{+} \mathrm{T}$ cells in PDAC, and over half of tumor-infiltrating $\mathrm{CD} 8^{+} \mathrm{T}$ cells were $\mathrm{CD} 8{ }^{+} \mathrm{CXCR} 5^{+} \mathrm{T}$ cells. Considering that $\mathrm{CXCL} 13$ is the only ligand for CXCR5, Tfh cells are likely to be the main contributor to the increased infiltration of CD8 ${ }^{+}$ $\mathrm{T}$ cells, which could provide a prerequisite for the reactivation of exhausted $\mathrm{CD} 8^{+} \mathrm{T}$ cells under humorally active conditions. Mouse Tfh cells do not secrete CXCL13 [14]; therefore, we could not simulate the anti-tumor process of human CXCL13 secreting Tfh cells in a mouse model. Instead, we explored the method of intravenous injection of CXCL13 into one of the experimental groups of mice to intervene in tumor growth. Indeed, rmCXCL13 could recruit $\mathrm{CD} 8^{+} \mathrm{T}$ cells and $\mathrm{B}$ cells and thus, control tumor growth, which further proved that Th cells can remodel the anti-tumor microenvironment function through CXCL13 in pancreatic cancer. Additionally, we simulated the anti-tumor effects of IL-21 secreted by Tfh cells to promote $\mathrm{B}$ cell maturation and antibody production in the other two experimental groups of mice. However, repeated injections of CXCL13 or IL-21 might produce systemic spikes of cytokine activity, which might not necessarily mimic the biological reality of cytokine production by Tfh cells; therefore, it is necessary to verify the in vivo function of Tfh cells in the specific environments of PDAC using an optimized mouse model.

TLSs have been a hotspot in the field of tumor immunology in recent years [13]. TLSs are important sites of T-B cell interactions, and their presence correlates with good prognosis across multiple tumor types [32-34]. In PDAC, the existence of tumor-associated TLSs usually indicates a longer anti-tumor immune response and better prognosis $[8,11]$. TLS formation in PDAC is critical for a successful immune response; however, the mechanism of TLS formation is unknown. The infiltration of $\mathrm{CD}^{+} \mathrm{T}$ cells and $\mathrm{B}$ cells in PDAC is closely related to TLSs [11,35]. Notably, our immunofluorescence results showed that Tfh cells tended to infiltrate in the microstructures aggregated with immune cells (Figure $1 \mathrm{~F}-\mathrm{H}$, left). Although the infiltration of B cells in these microstructures was not sufficient to identify them as the typical TLSs (data not shown), our observations confirmed the recruitment function of Tfh cells toward CD8 ${ }^{+} \mathrm{T}$ cells and B cells, hinting at a role for tumor-infiltrating Tfh cells in early-stage TLS formation, which is worthy of further in-depth exploration.

Persistently high expression of PD-1 is one of the characteristics of Tfh cells that distinguish them from other $\mathrm{CD} 4^{+} \mathrm{T}$ cell subgroups. In the germinal center, the expression of a normal level of PD-L1 can effectively prevent the overactivation of Tfh cells. Autoimmunity or poor-quality antibody responses could be caused by PD-1 deficiency $[36,37]$. However, in the immunosuppressive microenvironment, with an elevated level of PD-L1 in PDAC, the persistently high expression of PD-1 might lead to the function of Tfh cells being inhibited, representing a tool by which tumor cells achieve immune escape. In the present study, we found that Tfh cells promoted anti-tumor cellular immunity by increasing the infiltration of $\mathrm{CD} 8^{+} \mathrm{T}$ cells, and mediated anti-tumor humoral immunity by increasing the infiltration of $\mathrm{B}$ cells and promoting the maturation of $\mathrm{B}$ cells into plasma cells. Therefore, we hypothesized that the release of Tfh-mediated immunosuppression by immune check- 
point inhibitors could benefit patients with PDAC in terms of both anti-tumor cellular immunity and humoral immunity. Owing to the limited size of tumor samples, we could only verify the hypothesis using circulating Tfh cells from the peripheral blood of patients with PDAC. However, the mechanism by which the function of tumor-infiltrating Tfh cells is inhibited in PDAC deserves further research.

At present, the curative effect of immunotherapy for pancreatic cancer in the clinic is unsatisfactory. In view of the complex tumor microenvironment of pancreatic cancer, compared with immune checkpoint inhibitors or other immunotherapy methods, endogenous expansion and activation of tumor-infiltrating anti-tumor immune effector cells might represent a more effective strategy to establish a long-term and stable anti-tumor immune response. Further research on the anti-tumor effect of Tfh cells will help to deepen our understanding of the immunosuppressive mechanism in the tumor microenvironment of pancreatic cancer. Reversing the function of Tfh cells might promote the establishment of an immunoactive tumor microenvironment, as well as inducing a long-term anti-tumor immune response, which would be helpful to transform "cold tumors" into "hot tumors".

\section{Conclusions}

Taken together, Tfh cells played anti-tumor role via CXCL13-dependent recruitment of $\mathrm{CD}^{+} \mathrm{T}$ cells and B cells and IL-21-dependent B cell maturation. However, the anti-tumor function of Tfh cells was impaired by PD-L1 /PD-1 signaling in PDAC, which could be reversed using neoadjuvant chemotherapy. Our results uncovered a novel mechanism of immunosuppression mediated by Tfh cells, and provided new strategies for pancreatic cancer immunotherapy.

Supplementary Materials: The following are available online at https:/ / www.mdpi.com/article/10 $.3390 /$ cancers13153678/s1, Figure S1. (A)The strategy of gating Tfh cells, taking the peripheral blood sample as an example. Figure S2. (A) Analysis result of correlation between functional Tfh cells with CD8 ${ }^{+} \mathrm{T}$ cells from the public database (http://bioinfo.life.hust.edu.cn/web/ImmuCellAI/). Figure S3. (A) Representative flow cytometry data and (B) the proportion of Tfh cells (CD4 ${ }^{+} \mathrm{CXCR} 5^{+}$ $\left.\mathrm{PD}^{+}\right)$in $\mathrm{CD}^{+} \mathrm{T}$ cells from the peripheral blood of healthy donors $(n=14)$ and patients with PDAC at different stages $\left(n_{I}=11, n_{I I}=13, n_{I I I}=13\right)$. (C) Comparison of the proportion of CD8 ${ }^{+} \mathrm{T}$ cells and B cells recruited to the bottom of the Transwell chamber by cTfh cells between HC and PDAC for conditions treated with or without rhCXCL13 or anti-CXCL13 neutralizing antibodies. Table S1. Demographics and clinical characteristics of the cohort of patients with PDAC from whom were obtained fresh intra-tumor tissues and peripheral blood samples from $(n=62)$ in the study.

Author Contributions: Conceptualization, X.L., L.Y., X.W., X.Y. and L.L.; methodology, X.L., L.Y., Z.L, J.D., Y.Y., R.Z. and L.D.; software, X.L., R.Z., H.L., T.L., S.X., X.H., H.X. and W.W.; validation, X.L., L.Y. and P.L.; formal analysis, X.L., L.Y. and H.G.; investigation, X.L., L.Y., Z.L., J.D., W.Z. and H.G.; resources, Y.Y., P.L., L.D. and W.Z.; data curation, T.L., S.X. and X.H.; writing-original draft preparation, X.L. and L.Y.; writing-review and editing, X.L., L.Y., X.W., X.Y. and L.L.; supervision, H.L., H.X. and W.W.; project administration, H.G. and X.W; funding acquisition, X.Y. and L.L.; All authors have read and agreed to the published version of the manuscript.

Funding: This work was supported by grants from the National Science Foundation for Distinguished Young Scholars of China (81625016), the National Natural Science Foundation of China (81871941, 81872366, 81827807, 81802675, 81701630 and 81702341), the Outstanding Academic Leader Program of the "Technological Innovation Action Plan" in Shanghai Science and Technology Commission (18XD1401200), the Scientific Innovation Project of Shanghai Education Committee (2019-01-07-0007-E00057), the Natural Science Foundation of Shanghai (19ZR1410800), the Clinical and Scientific Innovation Project of Shanghai Hospital Development Center (SHDC12018109), and the Clinical Research Plan of Shanghai Hospital Development Center (SHDC2020CR1006A). This research received no external funding.

Institutional Review Board Statement: The experiments were conducted under protocols approved by the Ethics committee of Fudan University Shanghai Cancer Center (ethic code: FUSCC-IACUCS20210159, approved at 23 February 2021), and written informed consents was obtained from all patients and healthy donors. 
Informed Consent Statement: Informed consent was obtained from all subjects involved in the study.

Data Availability Statement: The data presented in this study are available on request from the corresponding author. The data are not publicly available due to privacy.

Conflicts of Interest: The authors declare no conflict of interest.

\section{References}

1. Jain, T.; Dudeja, V. The war against pancreatic cancer in 2020-Advances on all fronts. Nat. Rev. Gastroenterol. Hepatol. 2021, 18, 99-100. [CrossRef] [PubMed]

2. Bear, A.S.; Vonderheide, R.H.; O'Hara, M.H. Challenges and Opportunities for Pancreatic Cancer Immunotherapy. Cancer Cell 2020, 38, 788-802. [CrossRef]

3. Leinwand, J.; Miller, G. Regulation and modulation of antitumor immunity in pancreatic cancer. Nat. Immunol. 2020, 21, 1152-1159. [CrossRef] [PubMed]

4. Zhang, Y.; Velez-Delgado, A.; Mathew, E.; Li, D.; Mendez, F.M.; Flannagan, K.; Rhim, A.D.; Simeone, D.M.; Beatty, G.; Di Magliano, M.P. Myeloid cells are required for PD-1/PD-L1 checkpoint activation and the establishment of an immunosuppressive environment in pancreatic cancer. Gut 2017, 66, 124-136. [CrossRef]

5. Cartwright, A.N.R.; Suo, S.; Badrinath, S.; Kumar, S.; Melms, J.; Luoma, A.; Bagati, A.; Saadatpour, A.; Izar, B.; Yuan, G.-C.; et al. Immunosuppressive Myeloid Cells Induce Nitric Oxide-Dependent DNA Damage and p53 Pathway Activation in CD8(+) T Cells. Cancer Immunol. Res. 2021, 9, 470-485. [CrossRef]

6. Bayne, L.J.; Beatty, G.L.; Jhala, N.; Clark, C.E.; Rhim, A.D.; Stanger, B.Z.; Vonderheide, R.H. Tumor-derived granulocytemacrophage colo-ny-stimulating factor regulates myeloid inflammation and $\mathrm{T}$ cell immunity in pancreatic cancer. Cancer Cell 2012, 21, 822-835. [CrossRef]

7. Chen, Y.; Kim, J.; Yang, S.; Wang, H.; Wu, C.-J.; Sugimoto, H.; LeBleu, V.S.; Kalluri, R. Type I collagen deletion in $\alpha$ SMA+ myofibroblasts augments immune suppression and accelerates progression of pancreatic cancer. Cancer Cell 2021, 39, 548-565.e6. [CrossRef] [PubMed]

8. Hiraoka, N.; Ino, Y.; Yamazaki-Itoh, R.; Kanai, Y.; Kosuge, T.; Shimada, K. Intratumoral tertiary lymphoid organ is a favourable prognosticator in patients with pancreatic cancer. Br. J. Cancer 2015, 112, 1782-1790. [CrossRef]

9. Kang, Y.W.; Lee, J.E.; Jung, K.H.; Son, M.K.; Shin, S.M.; Kim, S.J.; Fang, Z.; Yan, H.H.; Park, J.H.; Han, B.; et al. KRAS targeting antibody synergizes anti-cancer activity of gem-citabine against pancreatic cancer. Cancer Lett. 2018, 438, 174-186. [CrossRef] [PubMed]

10. Spear, S.; Candido, J.B.; McDermott, J.R.; Ghirelli, C.; Maniati, E.; Beers, S.A.; Balkwill, F.R.; Kocher, H.M.; Capasso, M. Discrepancies in the Tumor Microenvironment of Spontaneous and Orthotopic Murine Models of Pancreatic Cancer Uncover a New Immunostimulatory Phenotype for B Cells. Front. Immunol. 2019, 10, 542. [CrossRef] [PubMed]

11. Gunderson, A.J.; Rajamanickam, V.; Bui, C.; Bernard, B.; Pucilowska, J.; Ballesteros-Merino, C.; Schmidt, M.; McCarty, K.; Philips, M.; Piening, B.; et al. Germinal center reactions in tertiary lymphoid structures associate with neoantigen burden, humoral immunity and long-term survivorship in pancreatic cancer. Oncoimmunology 2021, 10, 1900635. [CrossRef]

12. Vinuesa, C.G.; Linterman, M.A.; Yu, D.; MacLennan, I.C. Follicular Helper T Cells. Annu. Rev. Immunol. 2016, 34, 335-368. [CrossRef] [PubMed]

13. Sautès-Fridman, C.; Petitprez, F.; Calderaro, J.; Fridman, W.H. Tertiary lymphoid structures in the era of cancer immunotherapy. Nat. Rev. Cancer 2019, 19,307-325. [CrossRef] [PubMed]

14. Crotty, S. T Follicular Helper Cell Biology: A Decade of Discovery and Diseases. Immunity 2019, 50, 1132-1148. [CrossRef]

15. Bindea, G.; Mlecnik, B.; Tosolini, M.; Kirilovsky, A.; Waldner, M.; Obenauf, A.C.; Angell, H.; Fredriksen, T.; Lafontaine, L.; Berger, A.; et al. Spatiotemporal dynamics of intratumoral im-mune cells reveal the immune landscape in human cancer. Immunity 2013, 39, 782-795. [CrossRef]

16. Gu-Trantien, C.; Loi, S.; Garaud, S.; Equeter, C.; Libin, M.; De Wind, A.; Ravoet, M.; Le Buanec, H.; Sibille, C.; Manfouo-Foutsop, G.; et al. CD4+ follicular helper T cell infiltration predicts breast cancer survival. J. Clin. Investig. 2013, 123, 2873-2892. [CrossRef] [PubMed]

17. Duan, Z.; Gao, J.; Zhang, L.; Liang, H.; Huang, X.; Xu, Q.; Zhang, Y.; Shen, T.; Lu, F. Phenotype and function of CXCR5+CD45RA-CD4+ T cells were altered in HBV-related hepatocellular carcinoma and elevated serum CXCL13 predicted better prognosis. Oncotarget 2015, 6, 44239-44253. [CrossRef] [PubMed]

18. Ma, Q.-Y.; Huang, D.-Y.; Zhang, H.-J.; Chen, J.; Miller, W.; Chen, X.-F. Function of follicular helper T cell is impaired and correlates with survival time in non-small cell lung cancer. Int. Immunopharmacol. 2016, 41, 1-7. [CrossRef] [PubMed]

19. Jia, Y.; Zeng, Z.; Li, Y.; Li, Z.; Jin, L.; Zhang, Z.; Wang, L.; Wang, F.-S. Impaired function of CD4+ T follicular helper (Tfh) cells associated with hepa-tocellular carcinoma progression. PLoS ONE 2015, 10, e0117458.

20. Zhou, Z.-Q.; Tong, D.-N.; Guan, J.; Tan, H.-W.; Zhao, L.-D.; Zhu, Y.; Yao, J.; Yang, J.; Zhang, Z.-Y. Follicular helper T cell exhaustion induced by PD-L1 expression in hepatocellular carcinoma results in impaired cytokine expression and B cell help, and is associated with advanced tumor stages. Am. J. Transl. Res. 2016, 8, 2926-2936. [PubMed]

21. ImmuCellAI. Available online: http:/ / bioinfo.life.hust.edu.cn/web/ImmuCellAI (accessed on 24 March 2020). 
22. Birnbaum, D.J.; Finetti, P.; Lopresti, A.; Gilabert, M.; Poizat, F.; Turrini, O.; Raoul, J.-L.; Delpero, J.-R.; Moutardier, V.; Birnbaum, D.; et al. Prognostic value of PDL1 expression in pancreatic cancer. Oncotarget 2016, 7, 71198-71210. [CrossRef]

23. van der Leun, A.M.; Thommen, D.S.; Schumacher, T.N. CD8(+) T cell states in human cancer: Insights from single-cell analysis. Nat. Rev. Cancer 2020, 20, 218-232. [CrossRef]

24. Huntington, N.D.; Cursons, J.; Rautela, J. The cancer-natural killer cell immunity cycle. Nat. Rev. Cancer 2020, 20 , 437-454. [CrossRef]

25. Borst, J.; Ahrends, T.; Babała, N.; Melief, C.J.M.; Kastenmüller, W. CD4(+) T cell help in cancer immunology and immunotherapy. Nat. Rev. Immunol. 2018, 18, 635-647. [CrossRef]

26. Umeshappa, C.S.; Nanjundappa, R.H.; Xie, Y.; Freywald, A.; Xu, Q.; Xiang, J. Differential requirements of CD4+ T-cell signals for effector cytotoxic T-lymphocyte (CTL) priming and functional memory CTL development at higher CD8+ T-cell precursor frequency. Immunology 2013, 138, 298-306. [CrossRef]

27. Yang, M.; Lu, J.; Zhang, G.; Wang, Y.; He, M.; Xu, Q.; Xu, C.; Liu, H. CXCL13 shapes immunoactive tumor microenvironment and enhances the efficacy of PD-1 checkpoint blockade in high-grade serous ovarian cancer. J. Immunother. Cancer 2021, 9, e001136. [CrossRef]

28. Groeneveld, C.S.; Fontugne, J.; Cabel, L.; Bernard-Pierrot, I.; Radvanyi, F.; Allory, Y.; de Reyniès, A. Tertiary lymphoid structures marker CXCL13 is associated with better survival for patients with advanced-stage bladder cancer treated with immunotherapy. Eur. J. Cancer 2021, 148, 181-189. [CrossRef]

29. Rouanne, M.; Arpaia, N.; Marabelle, A. CXCL13 shapes tertiary lymphoid structures and promotes response to immunotherapy in bladder cancer. Eur. J. Cancer 2021, 151, 245-248. [CrossRef]

30. Gu-Trantien, C.; Migliori, E.; Buisseret, L.; de Wind, A.; Brohée, S.; Garaud, S.; Noel, G.; Chi, V.L.D.; Lodewyckx, J.-N.; Naveaux, C.; et al. CXCL13-producing TFH cells link immune sup-pression and adaptive memory in human breast cancer. JCI Insight 2017, 2, e91487. [CrossRef]

31. Bai, M.; Zheng, Y.; Liu, H.; Su, B.; Zhan, Y.; He, H. CXCR5+ CD8+ T cells potently infiltrate pancreatic tumors and present high functionality. Exp. Cell Res. 2017, 361, 39-45. [CrossRef]

32. Helmink, B.A.; Reddy, S.M.; Gao, J.; Zhang, S.; Basar, R.; Thakur, R.; Yizhak, K.; Sade-Feldman, M.; Blando, J.; Han, G.; et al. B cells and tertiary lymphoid structures promote immuno-therapy response. Nature 2020, 577, 549-555. [CrossRef] [PubMed]

33. Petitprez, F.; de Reyniès, A.; Keung, E.Z.; Chen, T.W.; Sun, C.M.; Calderaro, J.; Jeng, Y.-M.; Hsiao, L.-P.; Lacroix, L.; Bougouin, A.; et al. B cells are associated with survival and immuno-therapy response in sarcoma. Nature 2020, 577, 556-560. [CrossRef] [PubMed]

34. Cabrita, R.; Lauss, M.; Sanna, A.; Donia, M.; Larsen, M.S.; Mitra, S.; Johansson, I.; Phung, B.; Harbst, K.; Vallon-Christersson, J.; et al. Tertiary lymphoid structures improve immunotherapy and survival in melanoma. Nature 2020, 577, 561-565. [CrossRef] [PubMed]

35. Masugi, Y.; Abe, T.; Ueno, A.; Fujii-Nishimura, Y.; Ojima, H.; Endo, Y.; Fujita, Y.; Kitago, M.; Shinoda, M.; Kitagawa, Y.; et al. Characterization of spatial distribution of tu-mor-infiltrating CD8(+) T cells refines their prognostic utility for pancreatic cancer survival. Mod. Pathol. 2019, 32, 1495-1507. [CrossRef] [PubMed]

36. Kawamoto, S.; Tran, T.H.; Maruya, M.; Suzuki, K.; Doi, Y.; Tsutsui, Y.; Kato, L.M.; Fagarasan, S. The Inhibitory Receptor PD-1 Regulates IgA Selection and Bacterial Composition in the Gut. Science 2012, 336, 485-489. [CrossRef] [PubMed]

37. Shi, J.; Hou, S.; Fang, Q.; Liu, X.; Liu, X.; Qi, H. PD-1 Controls Follicular T Helper Cell Positioning and Function. Immunity 2018, 49, 264-274.e4. [CrossRef] 